\title{
Biosensor-based assay of exosome biomarker for early diagnosis of cancer
}

\author{
Ying Deng, Zhaowei Sun, Lei Wang, Minghui Wang, Jie Yang, Genxi Li (ه) \\ State Key Laboratory of Pharmaceutical Biotechnology, School of Life Sciences, Nanjing University, Nanjing 210023, China \\ (C) The Author(s) 2021. This article is published with open access at link.springer.com and journal.hep.com.cn
}

\begin{abstract}
Cancer imposes a severe threat to people's health and lives, thus pressing a huge medical and economic burden on individuals and communities. Therefore, early diagnosis of cancer is indispensable in the timely prevention and effective treatment for patients. Exosome has recently become an attractive cancer biomarker in noninvasive early diagnosis because of the unique physiology and pathology functions, which reflects remarkable information regarding the cancer microenvironment, and plays an important role in the occurrence and evolution of cancer. Meanwhile, biosensors have gained great attention for the detection of exosomes due to their superior properties, such as convenient operation, real-time readout, high sensitivity, and remarkable specificity, suggesting promising biomedical applications in the early diagnosis of cancer. In this review, the latest advances of biosensors regarding the assay of exosomes were summarized, and the superiorities of exosomes as markers for the early diagnosis of cancer were evaluated. Moreover, the recent challenges and further opportunities of developing effective biosensors for the early diagnosis of cancer were discussed.
\end{abstract}

Keywords biosensor; exosome; cancer diagnosis

\section{Introduction}

Cancer, an urgent global public health issue, constantly threats all human beings, and the survival rate of patients still could not be greatly improved over the past few years, partly due to the late discovery of cancer [1]. Therefore, the progressive development of early diagnosis and treatment of cancer has brought dawn for human beings to overcome cancer [2]. However, traditional cancer diagnostic methods not only are expensive but also require advanced instruments and professional medical staff, especially some methods that need invasive sampling [3]. Therefore, an urgent need for non-invasive, cost-effective, and easyoperation methods for tumor diagnosis exists. At present, the biomarker-based liquid biopsy is a hotspot in the early diagnosis of cancer; it has the salient characteristics of minimally invasive and repeated sampling. It could also comprehensively reflect the state information of tumor cell state $[2,4]$ and pave the way for precision treatment and personalized medicine [5]. Thus far, several novel biomarkers specific to various cancers in fluid circulation

Received April 15, 2021; accepted July 30, 2021

Correspondence: Genxi Li, genxili@nju.edu.cn have been found and played important roles in cancer diagnosis, especially exosome [6,7], of which superiorities lie in comprehensive information, high content in biofluids $\left(1 \times 10^{9}\right.$ particles $/ \mathrm{mL}$ in the blood), abundant cargos, stable circulation, easy capture, and enrichment of surface proteins.

Exosomes contain many kinds of contents, such as nucleic acids [8], lipids [9], and proteins [10], which all play critical roles in performing special biological functions $[11,12]$. Various studies have revealed that exosomes are associated with the pathogenesis and progress of cancer [13-15]. Moreover, cancer cells may secrete more cancerrelated exosomes than normal cells [16]. Therefore, detecting and monitoring exosomes and their contents could be a promising approach to screen cancer in liquid biopsy [17].

Researchers have investigated many methods to detect exosomes, including Western blotting (WB), ELISA [18], nanoparticle tracking analysis (NTA) $[19,20]$, flow cytometry [21], and mass spectrometry [22]. Although these conventional quantitative methods are widely used, they have some shortcomings and limitations. For example, NTA could determine exosome purity, concentration, and size distribution, but it could not distinguish the phenotype within complicated samples $[20,23]$. Although ELISA and 
WB could identify the protein information of exosomes, they are unable to quantify the concentration [24]. Besides, the promotion of these methods is dragged down by the problems of cumbersome operation, complicated sample pretreatment, and expensive analytical instruments [2527]. Identifying the exosomes in body fluids with fast and cost-effective approaches is urgent for the early diagnosis of patients with cancer [28], especially those who lived in resource-poor regions [29].

A biosensor is a sophisticated system applied to detect a specific biological analyte by converting bio-recognition events into measurable signals. Biosensors are nowadays ubiquitous in many areas, especially in biomedical research, disease diagnosis [30], food safety [31], and drug discovery [32]. As a promising candidate for conquering the challenges at this stage, biosensors could boost the field of liquid biopsy [33,34] owing to their small size, fast response, and high sensitivity [6,35]. In the past years, researchers have proposed a large number of biosensors for exosome assays with extraordinary performance and then applied them in medical and biological fields [34,36]. The advancement in clinical molecular diagnosis enables enhanced prediction of clinical outcome, increased reasonable patient stratification, and enhanced treatment decision-making, which has brought substantial benefits to patients [37].

Several reviews that refer to exosome detection have been recently published $[28,35,38]$. The present article focused on the superiorities of exosomes acting as a biomarker in cancer diagnosis, and various types of biosensors, including electrochemical biosensor, colorimetric biosensors, fluorescence-based biosensors, surface plasmon resonance (SPR)-based biosensors, surfaceenhanced Raman scattering (SERS)-based biosensors, and microfluidic-based biosensors, were comprehensively summarized, with an emphasis on their analytical performances and further challenges in the clinic diagnosis of cancer and the potential solutions.

\section{Exosome biology, role, and function}

Exosomes are a kind of biological extracellular vehicles secreted by cells and coated with bilateral phospholipid membranes [12]. These vesicles, with a diameter of 60 $100 \mathrm{~nm}$, circulate in almost all kinds of body fluids [39] and serve as messengers in the intercellular communication. They are also associated with extracellular matrix remodeling $[14,40]$. The definition of exosome changes with increasing investigation. The description of small vesicles in biological fluids could be traced back to the late 1960 s, when they were considered as a waste released by platelets [41]. In 1985, Johnstone et al. discovered a kind of small vesicles in the multivesicular bodies of reticulocytes that could be released to extracellular surroundings, and then termed this small vesicle as "exosome" [42]. Thereafter, these unique vesicles have been found in various body fluids, such as blood, saliva, semen, amniotic fluid, ascites, urine, cerebrospinal fluid, breast milk, and bile $[43,44]$.

Exosomes contain thousands of proteins, nucleic acids, metabolites, and lipids, which could all be transferred into cells and affect specific physiologic and pathological processes in organisms. They could participate in mammalian reproduction and development [44,45], immune responses [46], bacterial infection [47], and viral infection [48]. They are also involved in the metabolic process [49], the protection of cardiovascular fitness [50], and neurodegeneration modulation [51]. Exosomes are related to cancer origin and development [52]. In particular, exosomes could modulate immune surveillance [53] and promote cell migration [54], invasion [55], epithelialmesenchymal transition $[14,15]$, and phenotypic transformation [56].

The abundant biological molecules in exosomes also play important roles in disease diagnosis. For example, the proteins of exosomes reflecting the biological information of their parent cells could affect the functions and physiology of recipient cells. Therefore, exosomal proteins have been used as tools for diagnosis, especially in cancers, such as lung cancer [57], pancreatic cancer [58], gastric cancer [59], colorectal cancer (CRC) [16], breast cancer [60], and ovarian cancer [61] (Table 1). It is notable that exosomal surface proteins could serve as surface markers to facilitate the enrichment of cancer cell-derived exosomes. Exosomes also contain several nucleic acids. For instance, miRNAs could circulate stably in serum and enter into the adjacent cells, affecting the gene expression of recipient cells [62]. Meanwhile, the composition and amount of exosomal miRNAs in normal cells differ from those in cancer cells, suggesting their potential in the early diagnosis of cancer [63]. Thus far, several exosomal miRNAs have been deemed as biomarkers in diverse cancers (Table 2), such as prostate cancer [64], cervical carcinoma [65], and pancreatic cancer [66]. Exosomal contents may provide significant and specific information regarding the tumor microenvironment. Therefore, exosomes, which are involved in a series of physiology and pathology processes, have become a star in clinical study at present [67]. Their applications in the early diagnosis of cancer are increasing considerably [68].

\section{Electrochemical biosensors}

Electrochemical biosensors have been applied in exosome detection because of their advantages, such as good adaptability, high sensitivity, facile operation, great convenience, fast, and low cost, making them quickly adapt to clinical settings $[75,76]$. An electrochemical biosensor is 
Table 1 Exosomal proteins as tumor biomarkers

\begin{tabular}{|c|c|c|c|c|c|}
\hline Exosomal proteins & Pathophysiology & Source & Isolation method & Year & References \\
\hline CD91, CD317, and EGFR & Lung cancer & Plasma & Extracellular vehicles array & 2015 & {$[57]$} \\
\hline LRG1 & Lung cancer & Urine & Ultracentrifugation & 2011 & [69] \\
\hline NY-ESO-1 & Lung cancer & Plasma & Extracellular vehicles array & 2016 & {$[10]$} \\
\hline LESP-1 & Lung cancer & Plasma & Exclusion chromatography & 2020 & {$[70]$} \\
\hline GPC1 & Pancreatic cancer & Serum & Flow cytometry & 2015 & {$[58]$} \\
\hline GKN1 & Gastric cancer & Serum & Ultracentrifugation & 2018 & [59] \\
\hline CEA & Colorectal cancer & Serum & Ultracentrifugation & 2012 & {$[16]$} \\
\hline CD147 & Colorectal cancer & Plasma & Ultracentrifugation & 2018 & [71] \\
\hline Survivin-2B & Breast cancer & Serum & Ultracentrifugation & 2014 & {$[72]$} \\
\hline $\mathrm{FR} \alpha$ & Ovarian cancer & Plasma & Microfluidic chip & 2019 & {$[61]$} \\
\hline
\end{tabular}

Table 2 Exosomal miRNAs as tumor biomarkers

\begin{tabular}{llllll}
\hline Exosomal miRNAs & Pathophysiology & Source & Isolation method & Year & References \\
\hline $\begin{array}{l}\text { miR-21, miR-141, miR-200a, miR-200c, } \\
\text { miR-200b, miR-203, miR-205, and }\end{array}$ & Ovarian cancer & Plasma & Modified MACS ${ }^{\mathrm{a}}$ & 2008 & \\
miR-214 & & & & & \\
$\begin{array}{l}\text { miR-19b-3p, miR-584-5p, miR-425-5p, } \\
\text { miR-221-3p, miR-409-3p, and }\end{array}$ & Lung adenocarcinoma & Plasma & ExoQuick & 2016 & {$[74]$} \\
miR-21-5p & & & & & \\
miR-141 & Prostate cancer & Serum & ExoQuick & 2015 & {$[64]$} \\
miR-221-3p & Cervical carcinoma & Serum & ExoQuick & 2019 & {$[65]$} \\
miR-301a-3p & Pancreatic cancer & Serum & Ultracentrifugation & 2018 & {$[66]$} \\
\hline
\end{tabular}

${ }^{\mathrm{a}} \mathrm{MACS}$, magnetic activated cell sorting.

mainly composed of two parts: a bio-recognition element and a transducer. After the exosomes in test samples are captured by specific bio-recognition elements, the transducers could translate the recognition event into electrochemical signals (amperometry, potentiometry, conductometry, and impedimetry). For the development of electrochemical biosensors, nucleic acid is a frequentlyused element in the fabrication of high-sensitivity electrochemical biosensor because of its ultra-high efficiency, base-pairing precision, and low cost [77]. Moreover, aptamer, which shows a strong affinity to specific proteins, has been widely used in the design of label-free electrochemical strategies for exosome detection [76]. Yin et al. proposed an aptamer-triggered, simple, and sensitive method by embedding doxorubicin into doublestrand DNA to serve as electrochemical signal reporters. After the aptamer-triggered method was combined with exonuclease III (Exo III)-assisted signal amplification, the limit of detection (LOD) was down to 12 particles/ $\mu \mathrm{L}$ [78]. Similarly, Dong et al. used the recognition capacity of aptamers to release several messenger DNAs and exploited Exo III to trigger the next round of signal amplification. The dual-signal amplification assay could determine targets as low as 70 particles/ $\mu \mathrm{L}$ [79]. Interestingly, by the virtue of two aptamers that could simultaneously bind to two proteins that coexist on the same exosome, Zhao et al. developed an ultrasensitive approach for exosome detection by using a target-triggered 3D DNA walking machine. The biosensor exhibited great analytical performance and obtained a detection limit of 14 particles $/ \mu \mathrm{L}$ under optimal conditions [80]. Wang et al. implemented a multidirectional hybridization chain reaction (HCR)-based electrochemical aptasensor to detect MCF-7 cell-derived EpCAM positive exosomes [81]. They used hydrophobic interaction between cholesterol anchor and exosomal lipid bilayer to trigger multidirectional HCR. This biosensor exhibited high sensitivity with an LOD of 285 particles $/ \mu \mathrm{L}$. Click chemistry has also been used for the design of biosensors. For instance, An et al. combined click chemistry and HCR reaction with a glassy carbon electrode for exosome measurements [82]. Instead of exploiting cholesterol to introduce the primer of HCR, this method was based on nonspecific capture (4-oxo-2-nonenal alkyne (alkynyl-4-ONE)), which could enhance the accuracy and sensitivity, with a low LOD of 96 particles/ $\mu \mathrm{L}$. Moreover, by introducing a DNA molecule machine in building a biosensor, Cao et al. proposed an amplified electrochemical detection method for exosome assay. The cascade toehold-mediated strand displacement reaction could continually introduce methylene blue (MB)-modified 
signal probes to generate enhanced signals [83]. Besides, to further improve the selectivity and efficiency of exosome assay for the early diagnosis of cancer, Huang et al. screened a gastric cancer exosome-specific aptamer towards Mucin 1 (MUC1), which could serve as a potential biomarker to predict the invasion of gastric cancer [84]. By further making use of rolling circle amplification (RCA) reaction, they acquired a low detection limit of 954 particles/mL [85]. Though the abovementioned nucleic acid-based signal amplification methods showed the superiorities of high sensitivity, high specificity, and low cost, they may suffer from relatively laborious sequence design. Wang et al. recently devised a spherical nucleic acid-based cascade signal amplification strategy for exosome detection. By the virtue of terminal deoxynucleotidyl transferase (TdT) and Exo III, a convenientoperated and highly sensitive method for the detection of exosomes without complicated nucleic acids sequence design was proposed, acquiring a low LOD of 44 particles/ $\mu \mathrm{L}[86]$.

In addition to DNA-based amplification, some nanomaterials have been used to improve the performance of biosensors [87]. For example, metal-organic frameworks (MOFs) have been explored for the fabrication of electrochemical biosensor owing to their excellent chemical tenability [88]. Sun et al. (Fig. 1A) designed an enzyme-free and label-free electrochemical biosensor by exploiting zirconium-based MOFs (Zr-MOFs) to sensitively detect glioblastoma-derived (GBM) exosomes [25]. In this ingenious design, the Zr-MOFs loaded with methylene blue molecules (MB@Zr-MOFs) could directly combine to GBM exosomes via the formation of $\mathrm{Zr}-\mathrm{O}-\mathrm{P}$ bonds [89]. When the GBM exosomes were selectively captured by a peptide ligand [90], the MB encapsulated in $\mathrm{Zr}-\mathrm{MOF}$ senerated a high electrochemical signal. Consequently, the detection could be obtained from $9.5 \times 10^{3}$ particles $/ \mu \mathrm{L}$ to $1.9 \times 10^{7}$ particles $/ \mu \mathrm{L}$, and the LOD was $7.83 \times 10^{3}$ particles $/ \mu \mathrm{L}$. The proposed strategy showed good versatility and effectiveness as it could be used to detect other disease biomarkers by simply replacing the capture sequences. MOFs could encapsulate diverse biological molecules due to the adjustable porosity [91] and release the contents in response to different endogenous or exogenous stimuli. Cao et al. (Fig. 1B) utilized a kind of $\mathrm{pH}$-responsive MOFs, zeolitic imidazolate framework-8, to pack horseradish peroxidase (HRP) and developed an electrochemical biosensor for accurate identification of PD-L1' exosomes in breast cancer [92]. By combining DNA amplification-controlled $\mathrm{pH}$ decreases with the virtue of MOF-mediated signal amplification, the obtained results of the biosensor showed an LOD of as low as 334 particles $/ \mathrm{mL}$ and a linear range of $1 \times 10^{3}-1 \times 10^{10}$ particles $/ \mathrm{mL}$. Covalent organic frameworks (COFs) have also been applied in sensor fabrication due to their admirable loading capacity, ordered crystal structure, and decent biocompatibility [93]. Wang et al. (Fig. 1C) designed an HRP-pSC 4 -AuNPs@COFs nanoprobe for the detection of CRC-derived exosomes [94]. In the presence of TMB and $\mathrm{H}_{2} \mathrm{O}_{2}$, the COFs endowed HRPs with high catalytic activity and produced an enhanced electrochemical signal. This biosensor showed excellent analytical performance, and it could measure exosomes in the range of $5 \times 10^{2}-5 \times 10^{7}$ particles $/ \mu \mathrm{L}$, with an LOD of 160 particles $/ \mu \mathrm{L}$. Some nanoparticles with peroxidasemimicking activity could also be used to build electrochemical biosensors. Shiddiky et al. recently utilized carboxyl group-functionalized iron oxide $\left(\mathrm{Fe}_{2} \mathrm{O}_{3}\right)$ nanoparticles (C-IONPs) for direct isolation and quantification of exosomes. By the virtue of carboxylic acid $-\mathrm{COOH}$ groups on the surface, the C-IONPs could be conjugated to CD9 and thus served as capture agents for exosome separation and purification. The selected nanomaterials could be used as dispersible nanocarriers and nanozymes, which realized the integration of isolation and detection [95].

Table 3 summarizes the abovementioned biosensors' performance. Electrochemical biosensors could be an undisputed useful technology for exosome assay due to their high sensitivity, rapid response, and cost-effective system $[35,96]$.

Table 3 Electrochemical biosensor for exosome detection

\begin{tabular}{|c|c|c|c|c|c|c|c|}
\hline Detection method & Target & Type of cancer & Sample & Recognition element & Signal element & LOD & References \\
\hline Electrochemistry & EGFRvIII/EGFR & Glioblastoma & Serum & Peptide & MB & $7.83 \times 10^{3}$ particles $/ \mu \mathrm{L}$ & [25] \\
\hline Electrochemistry & CD63 & Breast cancer & Serum & Aptamer & HRP-OPD & 96 particles $/ \mu \mathrm{L}$ & [82] \\
\hline Electrochemistry & EpCAM & Breast cancer & Serum & Aptamer & $\mathrm{HRP}-\mathrm{H}_{2} \mathrm{O}_{2}-\mathrm{TMB}$ & 285 particles $/ \mu \mathrm{L}$ & [81] \\
\hline Electrochemistry & MUC1 & Gastric cancer & Plasma & Aptamer/antibody & G-quadruplex $/ \mathrm{H}_{2} \mathrm{O}_{2}$ & 954 particles $/ \mathrm{mL}$ & [85] \\
\hline Electrochemistry & EpCAM & Colorectal cancer & Plasma & Aptamer & $\mathrm{MB}$ & 44 particles $/ \mu \mathrm{L}$ & [86] \\
\hline Electrochemistry & PD-L1/CD63 & Breast cancer & Serum & Aptamer/antibody & HRP-OPD & 334 particles $/ \mathrm{mL}$ & [92] \\
\hline Electrochemistry & CD63 & Colorectal cancer & Serum & Aptamer & HRP- $\mathrm{H}_{2} \mathrm{O}_{2}$-TMB & 160 particles $/ \mu \mathrm{L}$ & [94] \\
\hline Electrochemistry & CD9/CA-125 & Ovarian cancer & - & Antibody & $\mathrm{Fe}_{2} \mathrm{O}_{3}-\mathrm{H}_{2} \mathrm{O}_{2}-\mathrm{TMB}$ & $1.25 \times 10^{6}$ exosomes $/ \mathrm{mL}$ & [95] \\
\hline
\end{tabular}



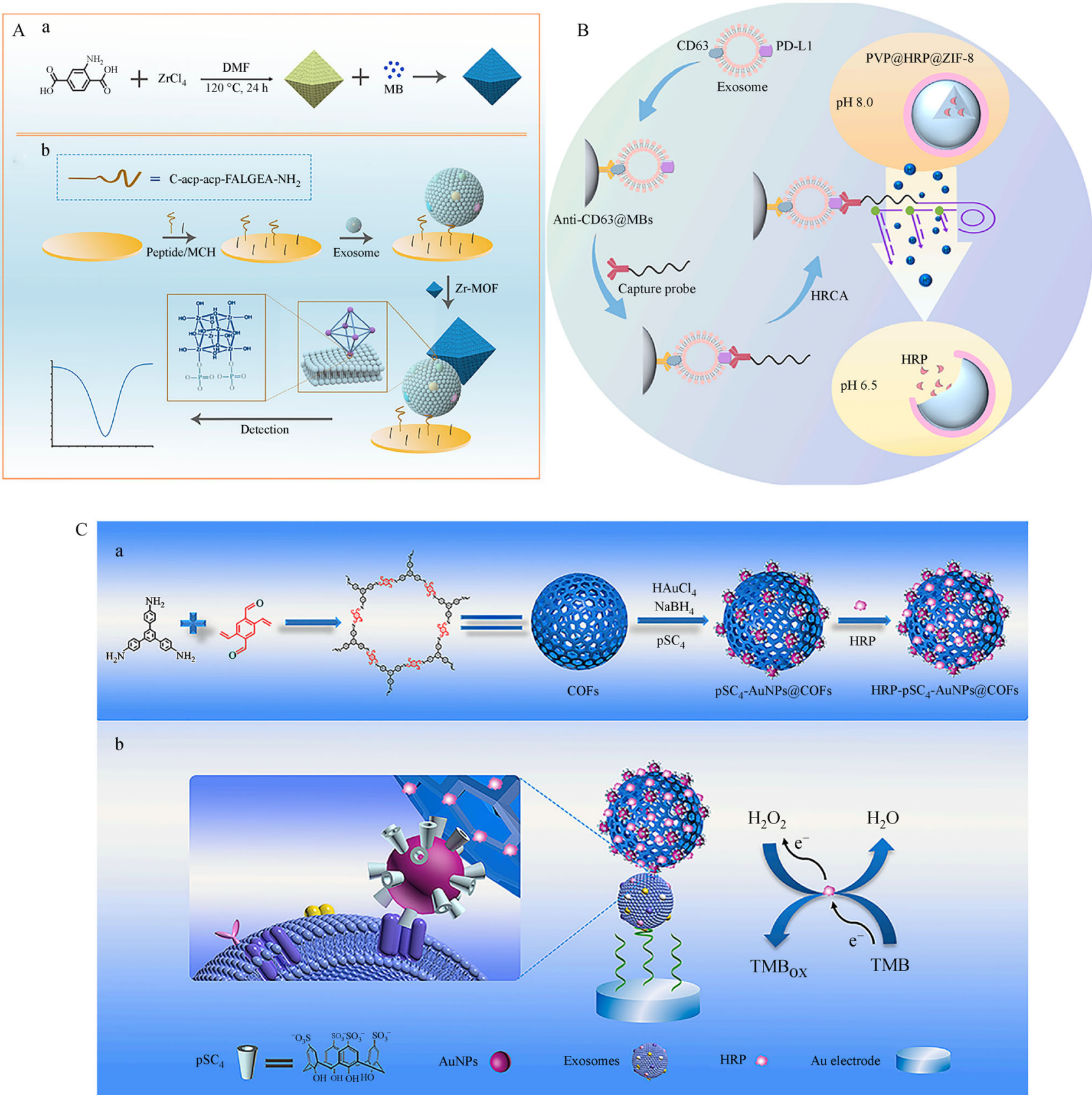

Fig. 1 Schematic of representative electrochemistry-based biosensors. (A) Detection of circulating exosomes by using zirconium-based metal-organic frameworks (Zr-MOFs). (a) Fabrication process of Zr-MOFs and Zr-MOFs loaded with methylene blue (MB@Zr-MOFs). (b) Process of electrochemical biosensor for exosome detection using MB@Zr-MOFs. (Reproduced with permission from Ref. [25]. Copyright 2020 American Chemical Society.) (B) Ultrasensitive electrochemical biosensor facilitated with DNA amplification-controlled $\mathrm{pH}$ decreases based on $\mathrm{pH}$-responsive MOFs encapsulated with horseradish peroxidase (HRP). (Reproduced with permission from Ref. [92]. Copyright 2020 Elsevier.) (C) Novel nanoprobe-based electrochemical assay for colorectal cancer-derived exosomes. (a) Fabrication process of covalent organic frameworks (COFs)-based nanoprobes. (b) Process of exosomes detection by using HRP-pSC4AuNPs@COFs nanoprobe. (Reproduced with permission from Ref. [94]. Copyright 2020 Elsevier.)

\section{Fluorescence-based biosensors}

Fluorescence-based methods have been widely used in biosensor development because of their simple operation, outstanding sensitivity, and cost effectiveness [97]. The three main methods for biosensor fabrication are fluorescence-based signal amplification, fluorescence resonance energy transfer (FRET), and fluorescence polarization. As an effective signal readout tool, fluorescence could be combined with various signal amplification strategies to 
fabricate sensitive biosensors for exosome detection [98]. $\mathrm{Li}$ and coworkers proposed several methods to use liposomes as an intriguing amplification element. For example, they used $\mathrm{Zr}^{4+}$ to serve as a bridge to link exosomes and liposomes due to the intrinsic combination of $\mathrm{Zr}^{4+}$ and the phosphate group outside vesicles. By the virtue of the interaction, exosomes could be detected conveniently without complicated operations [99]. The researchers also took advantage of aptamer-coated cationic liposome to further enhance the analytical performance [26]. In this work (Fig. 2A), TdT assisted with thioflavin T (ThT) were used to amplify the fluorescence signals. The LOD of this biosensor was 360 particles $/ \mu \mathrm{L}$, more sensitive than that in a previous report [100]. In addition, the researchers utilized the steric hindrance effect to control signal amplification and designed a simple and sensitive fluorescent biosensor (Fig. 2B). The attempt to detect exosomes on the account of its intrinsic steric hindrance effect was successful [101]. These studies have made full use of the own characteristics of exosomes, and they may bring more inspiration in the future for the construction of biosensors.

RCA is of great significance among nucleic acid-based signal amplification techniques, because it generates longstrand DNA at room temperature [102]. In a work performed by Huang et al. (Fig. 2C), an RCA reaction was introduced to generate many repeat sections for hybridization with a nanoprobe composed of gold nanoparticle (GNP)-DNA-fluorescent dye (FAM, GNPDNA-FAM). With the digestion of nicking endonuclease $(\mathrm{Nb} \cdot \mathrm{BbvCI})$, fluorescence signals continuously accumulated, and an LOD for 100 particles $/ \mu \mathrm{L}$ of exosome detection could be obtained [103]. Instead of the help of endonuclease to amplify the readout signal, a second primer was recently introduced to trigger a branched RCA to construct fluorescent biosensor; thus, the cost was cheaper and the operation was simpler than before, but the sensitivity was slightly weakened [104].

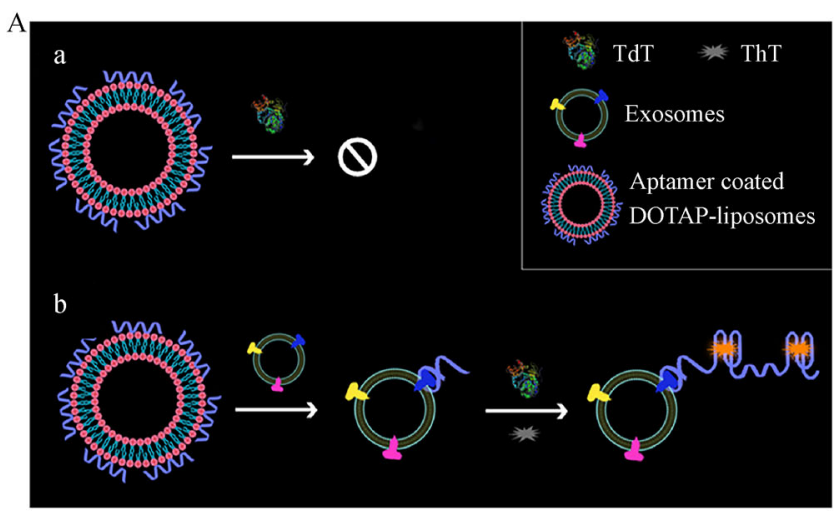

B

$\mathrm{C}$

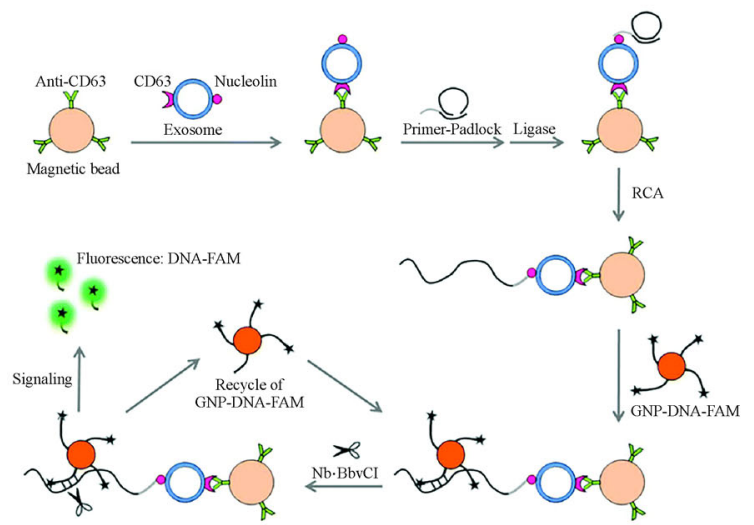

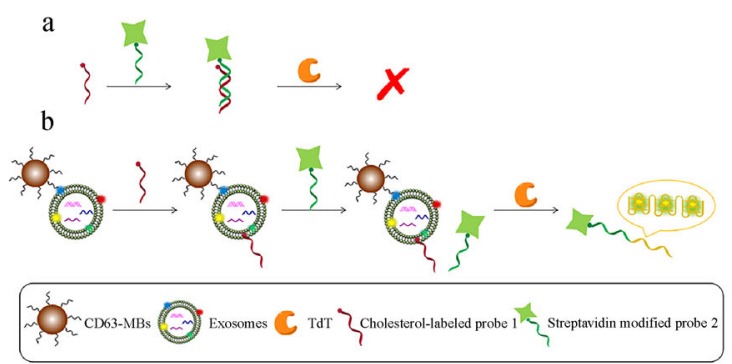

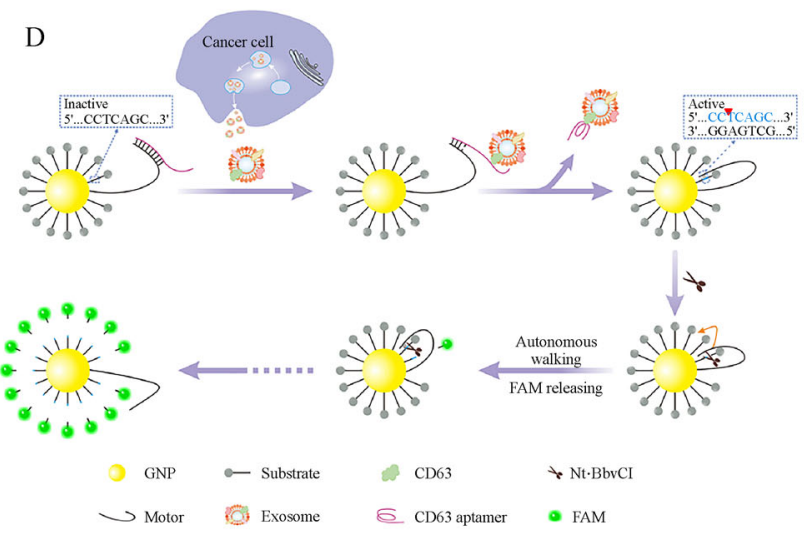

Fig. 2 Schematic of representative fluorescence-based biosensors. (A) Fabricating a cationic liposome for signal amplification detection of exosomes. Only in the presence of exosomes, the electrostatic attraction between aptamers and liposome broke down and then the free aptamers could trigger enzyme-mediated DNA extension to form multiple G-quadruplex. (Reproduced with permission from Ref. [26]. Copyright 2019 American Chemical Society.) (B) Simple and sensitive strategy for exosome detection utilizing steric hindrance-to-control signal amplification. (Adapted from Ref. [101], with permission from the Royal Society of Chemistry.) (C) Dual-signal amplification constructed using GNP-DNA-FAM conjugates hybridized with RCA technique (Adapted from Ref. [103], with permission from the Royal Society of Chemistry.) (D) Construction of exosome-triggered enzyme-powered DNA motors for sensitive exosome assay. (Reproduced with permission from Ref. [107]. Copyright 2020 Elsevier.) 
Concerning the fluorescent biosensors based on the FRET principle, Zhang et al. designed a "turn on" fluorescent aptasensor by selecting tetramethylrhodamine (TAMRA) as luminophore and Dabcyl as quenching group. Exosomes could break the hairpin structure of probes, leaving the TAMRA far away from the quencher, and then a strong fluorescence could be detected [105]. Li et al. combined another "fluorophore-quencher pair" (quencher (BHQ) and fluorescent dye (FITC)) with a superparamagnetic conjunction to construct a dual functional biosensor for the detection and capturing of exosomes from prostate cancer. Excellent diagnostic efficiency could be achieved with the elaborate design [106]. Yu et al. proposed a three-dimensional (3D) DNA motor-based biosensor for exosome assay (Fig. 2D). In this design, GNP was modified with carboxyl fluoresceinlabeled DNA strands to build DNA motors, which were locked with aptamer strands. Exosomes competitively bound to aptamers and triggered the DNA motor process, while restriction endonuclease $\mathrm{Nt} \cdot \mathrm{BbvCI}$ continually powered the FAM-labeled segment release. Compared with that in conventional ELISA, the LOD was fairly low (8.2 particles/ $\mu \mathrm{L})$ [107]. Li et al. constructed a facile fluorescent aptasensor, which was composed of aptamer, positively charged tertiary amine-containing tetraphenylethene (TPE-TA), and graphene oxide (GO), as recognition elements, fluorescent dye, and quencher, respectively. Numerous TPE-TAs bound one aptamer and aggregated together to produce amplified fluorescence signals in the presence of exosomes; otherwise, the signals were quenched by GO [108]. In a similar principle, Wang et al. used GO to absorb and quench fluorophore. With the assistance from an enzyme, an enlarged signal could be gained [47].

Through aptamer-based fluorescence polarization, Zhang et al. developed a simple, direct, and sensitive approach for exosome quantification in human plasma. Owing to the inherently huge mass/volume of exosomes, they could act as mass-based fluorescence polarization amplifiers to realize sensitivity detection. The assay achieved an LOD of 500 particles $/ \mu \mathrm{L}$ for lung cancerderived exosomes [109]. By simple mix-and-read, this method could detect exosomes in the biological matrix within approximately half an hour, without redundant separation or amplification procedures.

\section{Colorimetric biosensors}

Colorimetry exhibits attractive potential in biosensor construction due to its cost effectiveness, visual output, and simplicity. Colorimetric biosensors could transform the detection events into apparent color changes through two main approaches: distances or dispersion status change in nanomaterials and oxidation reactions mediated by enzymes [110,111]. Thus, nanomaterials and enzymes are commonly used as signal tags in colorimetric assay [112]. Given that the color changes in GNPs resulted from aggregation, Liu et al. proposed a colorimetric biosensor to detect exosomes through the combination of recombinase polymerase amplification with transcription-mediated amplification. They quantified the amplified surrogate DNA signal for exosome via GNP-based colorimetric assay. This design obtained a low LOD of 102 particle $/ \mathrm{mL}$ and thus may have a great potential in the early diagnosis of nasopharyngeal carcinoma [113]. Oxidation reactions could also be applied in colorimetric assay as the result of the color reaction between enzyme and substrate. For example, HRP could extensively accelerate the polymerization of colorless dopamine to produce a brown-black colored polydopamine (PDA) [114]. In accordance with this finding, $\mathrm{Xu}$ et al. (Fig. 3A) fabricated a colorimetric biosensor by introducing HRP to the surface of the exosomes and realized the detection within 10 min [111]. The sensitivity was further enhanced because the formed PDA could deposit around exosomes via the outstanding reactivity between PDA and amine, sulfhydryl, and the phenol groups of proteins [115]. The simple and costeffective colorimetric biosensor with an LOD of $7.77 \times$ $10^{3}$ particle $/ \mathrm{mL}$ deserved to be further studied to focus on the validation of clinical patient samples and the early detection of cancer. TMB is another common substrate of HRP. Chen et al. constructed a visible and colorimetric biosensor for the detection of exosomes by combining HRP catalysis and a $\mathrm{ZnO}$ nanowire-based 3D scaffold chip. Owing to the large surface area of $\mathrm{ZnO}$-chip device, the biosensor acquired an improved capture efficiency for exosome assay and an LOD of $2.2 \times 10^{4}$ particles $/ \mu \mathrm{L}$ [116]. He et al. also used TMB as the chromophore substrate to react with HRP for exosome detection. In this work, targets were first enriched by immunomagnetic beads and then inserted with a bivalent-cholesterol-labeled DNA to trigger the HRP-linked HCR for color reaction. The DNA nanostructure could load many HRPs for signal amplification, making the LOD down to $2.2 \times 10^{3}$ particles/ $\mu \mathrm{L}$ [117].

Some enzymes could be specifically used for the fabrication of colorimetric biosensors. For instance, Zhang et al. applied alkaline phosphatase (ALP) in the construction of biosensors $[118,119]$. They proposed a visual colorimetric method via ALP-induced silver deposition on gold nanorods (Au NRs) (Fig. 3B). An HCR process was involved here to accumulate ALP, which realized the multicolor visual detection of exosomes [118]. The operation was kind of complex, but the LOD could be as low as $1.6 \times 10^{2}$ particles $/ \mu \mathrm{L}$.

Although enzyme catalysis is one of the most common methods employed for the development of colorimetric biosensors, natural enzymes are complicated to purify and easily deactivated under harsh conditions, which may limit 
A

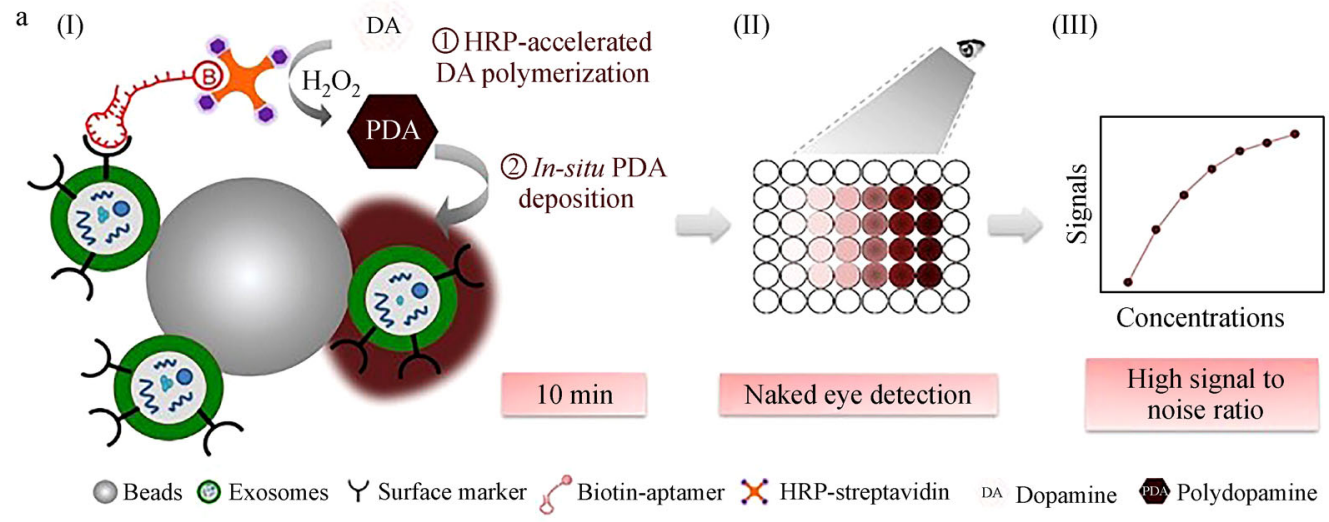

b
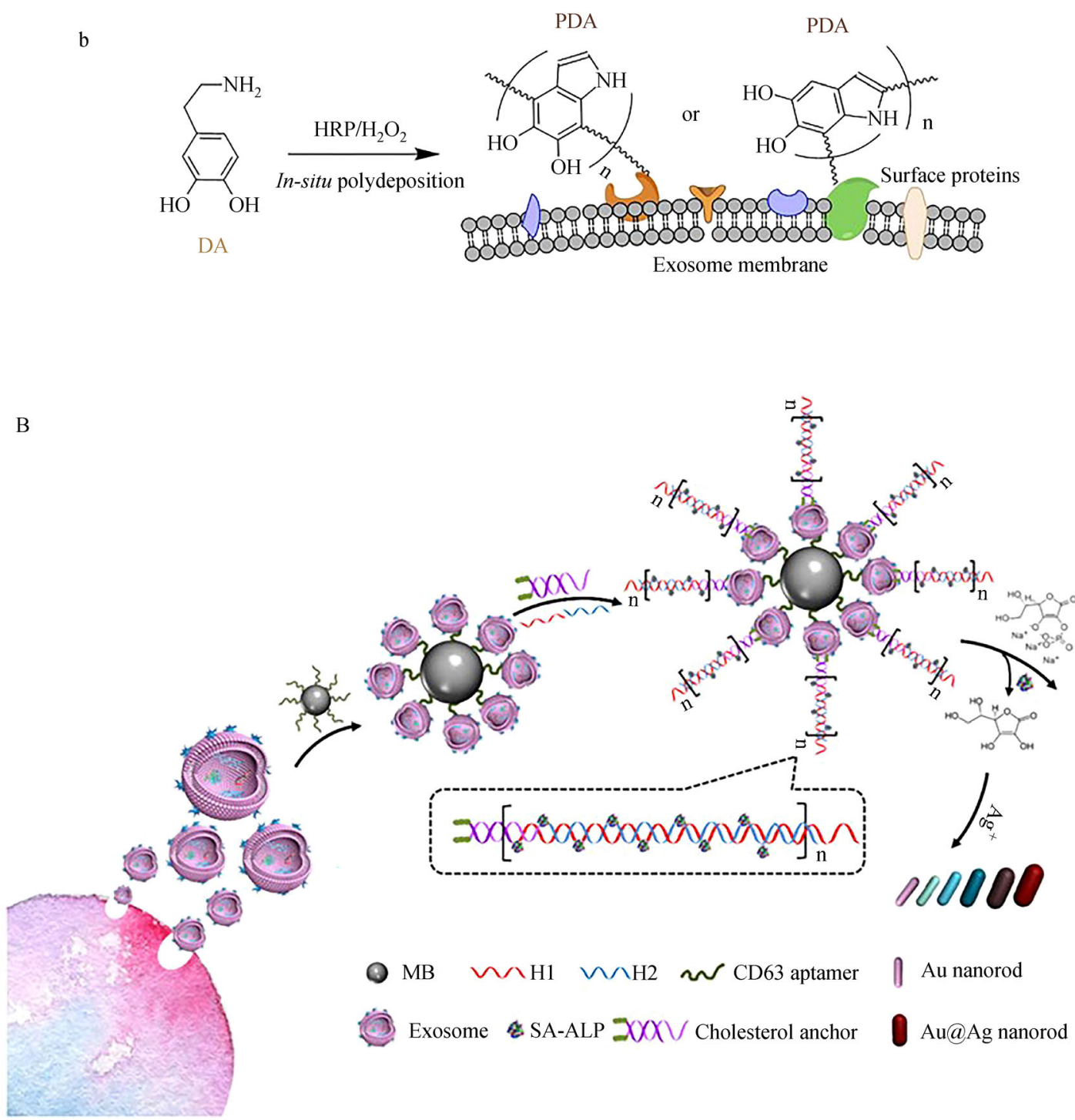

Fig. 3 Schematic of representative colorimetry-based biosensors. (A) Enzymatic catalysis-based dopamine polymerization and in-situ deposition for the design of colorimetric aptasensor for exosome detection. (a) Capturing target exosomes with latex beads and then using biotin-labeled aptamers to introduce streptavidin-labeled HRP to accelerate the polymerization of dopamine. A distinguishable color change could be seen, which could be strengthened by in-situ deposition of polydopamine around exosome particles. (b) Process of dopamine polymerization and polydopamine deposition on the surface of exosomes. Polydopamine could link to amine, sulfhydryl, and the phenol groups of proteins. (Reproduced with permission from Ref. [111]. Copyright 2020 Elsevier.) (B) Sensitive multicolor visual biosensor using a dual-signal amplification strategy of enzyme-catalyzed metallization of Au nanorods and hybridization chain reaction. (Reproduced with permission from Ref. [118]. Copyright 2019 American Chemical Society.) 
their application. Nanozymes with high chemical and thermal stability recently gained considerable attention in the construction of biosensors [120]. For example, $\mathrm{Fe}_{3} \mathrm{O}_{4}$ and $\mathrm{Fe}_{2} \mathrm{O}_{3}$ nanoparticles have high peroxidase activity; they could catalyze TMB from colorless to blue in the presence of $\mathrm{H}_{2} \mathrm{O}_{2}$. Therefore, by functionalization of iron oxide, aptamer-capped $\mathrm{Fe}_{3} \mathrm{O}_{4} \mathrm{NPs}$ [121] and gold-loaded ferric oxide nanocubes [122] have been used for the fabrication of a colorimetric biosensor to detect exosome. Wang et al. used $\mathrm{g}-\mathrm{C}_{3} \mathrm{~N}_{4} \mathrm{NSs}$ as nanozymes to build a "signal-off" colorimetric biosensor for exosome analysis. When exosomes despoiled the aptamers from the nanosheets, color change could be observed because of the decrease in the catalytic ability of nanozymes [123]. The peroxidase activity of single-walled carbon nanotubes was employed via aptamer absorption to develop an aptamer-based colorimetric biosensor [124]. This proposed method could be universally applicable for diverse exosome detection by simply changing the aptamer sequences. Moreover, hemin/G-quadruplex complex could catalyze the $\mathrm{H}_{2} \mathrm{O}_{2}$-mediated oxidation of TMB and produce an obvious color change; thus, it has also been used to realize colorimetric detection of exosomes [125].

\section{SPR-based biosensors}

SPR-based biosensors could detect molecular interactions by monitoring the refractive index changes on the surface of a thin gold layer, and they have been widely applied in biomolecule analysis in a real-time and label-free manner [126]. Many biological receptors, such as antibody, aptamer, and enzyme, have been employed to form SPR biosensors on the basis of distinctive optical phenomenon [127]. Moreover, SPR is highly sensitive to the binding events among the range of $200 \mathrm{~nm}$ on the gold layer [128]. This size closely fits with the dimension of exosomes. Thus, SPR-based biosensors have natural advantages for the assay of exosomes. Wang and coworkers designed an aptamer-based SPR biosensor for the highly sensitive detection of exosomes on the basis of dual GNP-assisted signal amplification [129]. In the presence of exosomes, a single AuNP-amplified SPR signal could be achieved through the complementary base hybridization (Fig. 4A). This enzyme-free method may reduce constraints on the detection conditions and offer opportunities for the development of exosome-based disease diagnostics. Unlike using GNPs for SPR signal enhancement, $\mathrm{Wu}$ et al. reported a localized surface plasmon resonance (LSPR) biosensor with self-assembly gold nanoislands for the detection and discrimination of different extracellular vesicles (A-549, SH-SY5Y) [130]. Later, they developed biotinylated antibody-functionalized titanium nitride (BAF-TiN) biosensor for high-performance label-free detection of human glioma cell line-derived exosomes
(Fig. 4B) [131]. In this biosensor, they used TiN as alternative plasmonic supporting material rather than gold and silver substrate, showing tunable plasmonic properties in the visible and near-infrared spectra. Meanwhile, biotinylated anti-EGFRvIII antibody could be immobilized on TiN surface on the basis of high-affinity biotin-TiN interaction, which could solve the problem of surface functionalization to TiN. The proposed BAF-TiN structure also exhibited excellent sensitivity and selectivity towards GM-derived exosomes. The latter work acquired higher accuracy than the previous one of the researchers, and it could have a great potential for exosomal surface protein analysis. For multiplex analysis of different exosome proteins, Im et al. reported a high-throughput, label-free nano-plasmonic exosome assay for quantitative analysis of exosomes on the basis of transmission SPR through periodic nanohole arrays [132]. Antibody-functionalized array could profile the exosome surface proteins with improved sensitivity over other methods. It integrated with miniaturized optics to enable portable operation. This biosensor could identify ovarian cancer cell-derived exosomes through analysis of CD24 and EpCAM membrane proteins. Due to the characteristics of labelfree and real-time measurement, SPR-based biosensors have been rapidly developed and made great progress for the detection of exosomes. However, most of SPRbiosensors are employed only for purified exosome samples prepared via ultracentrifugation, which may cause the detection process to be time consuming. Another limitation of SPR biosensor is the inability for multiplex analysis of exosomes.

\section{SERS-based biosensors}

For the detection of low-amount biomarkers, Raman scattering or SERS is a powerful plasmonic technique that is also a popular optical method because of its remarkable potential to enhance signals. A SERS-based biosensor is mainly composed of two parts: a substrate fixed with recognition elements and SERS nanoprobes modified with signal elements, and a sensor system that could form a typical sandwich in the presence of the target. SERS-based biosensors could identify distinctive spectral signals in the changeable and complicated biological environment compared with SPR or fluorescence [133]. It has been applied for the analysis of biomolecules, cellular imaging, and environmental monitoring [134].

SERS-based biosensors have also been employed to detect exosomes, with the advantages of rapid speed, high sensitivity, and multiplex analysis ability. Meanwhile, some nanomaterials have been used to improve the performance of these biosensors. Among them, $\mathrm{Au}$ nanomaterial is widely used for signal enhancement in SERS-based biosensors. Wang and coworkers proposed a 


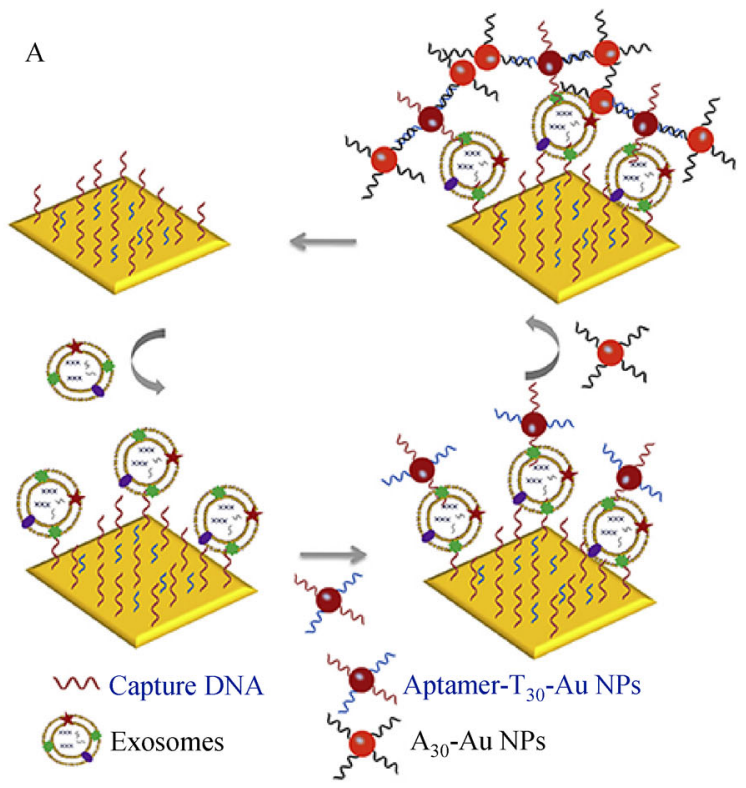

B

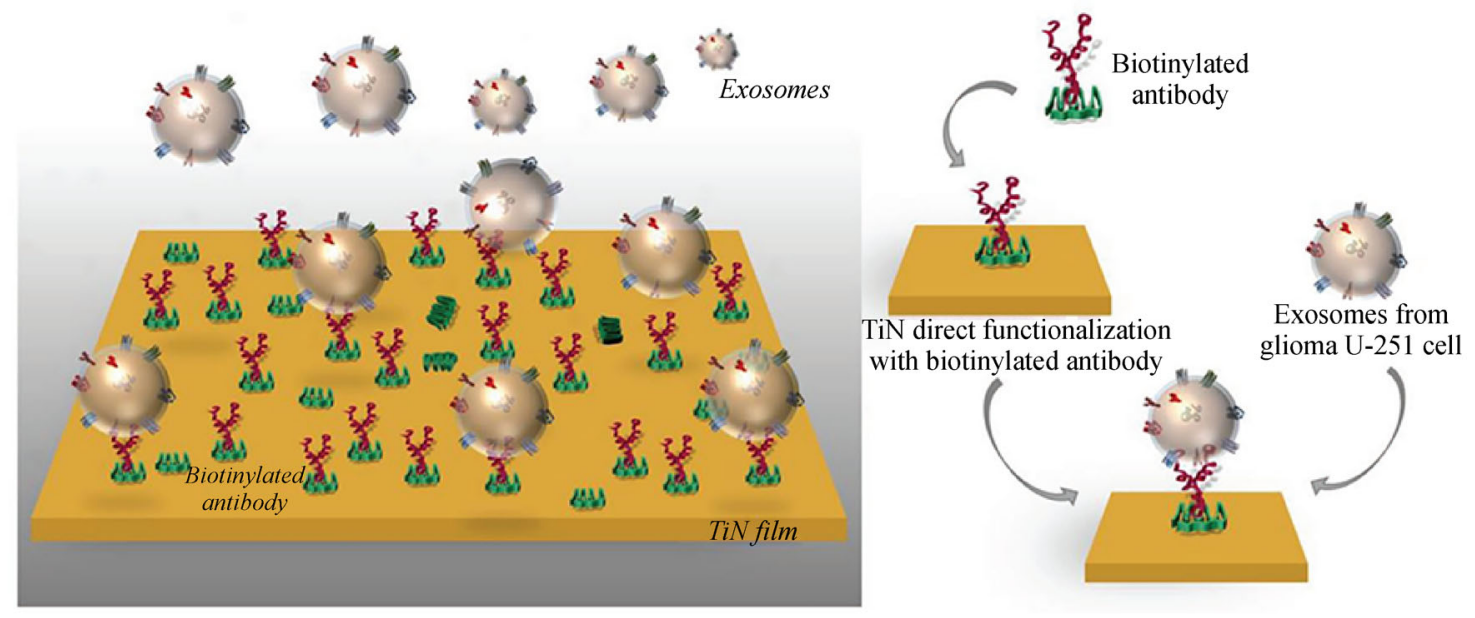

Fig. 4 Schematic of representative SPR-based biosensors. (A) Determination of cancerous exosomes based on dual AuNP-assisted signal amplification. (Reproduced with permission from Ref. [129]. Copyright 2019 Elsevier.) (B) Detection of glioma cells derived exosomes via biotinylated anti-CD63 antibody functionalized with titanium nitride (TiN). (Reproduced with permission from Ref. [131]. Copyright 2019 Wiley.)

SERS-based biosensor for simultaneous multiple detections of exosomes by using SERS probes (Fig. 5A) [135]. The SERS probe was prepared via GNP decorated with a Raman reporter and an aptamer for targeting a particular exosome. This biosensor could simultaneously detect multiple kinds of exosomes on the basis of three kinds of SERS probes designed using different SERS reporters. It could also distinguish the species of the target exosomes in one step. Zong et al. proposed a sandwich-type immunocomplex including SERS nanoprobes and magnetic nanobeads for the detection of tumor cell-derived exosomes (Fig. 5B) [136]. The SERS nanoprobe comprised gold core-silver shell NRs (Au@Ag NRs), Raman molecules, and a silica layer, which was decorated with antibody to specifically capture exosomes. SERS signals could be detected only in the presence of exosomes by forming sandwich-type immunocomplexes. The formation of GNPs could be varied in different strategies. For instance, Au NRs instead of spherical GNPs coated with QSY21 as SERS probes were used for quantitative detection of exosome proteins [137]. This designed device could analyze over 80 purified samples, with a detection limit of $2 \times 10^{6}$ exosomes $/ \mathrm{mL}$ in $2 \mathrm{~h}$. It required initial exosome isolation and could be further improved by 
A

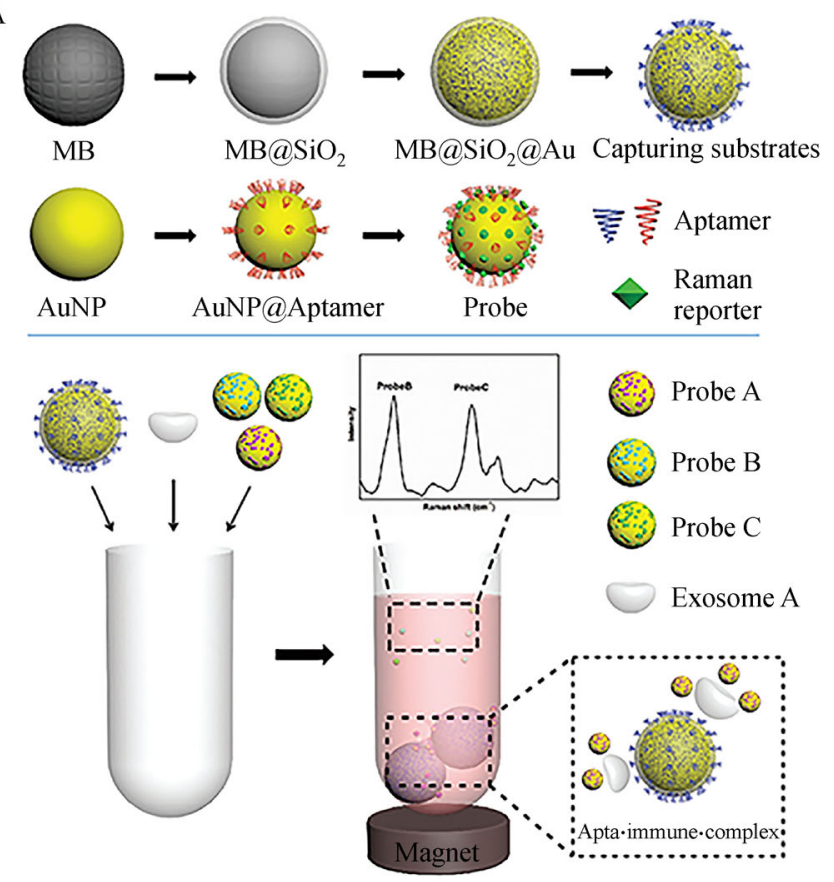

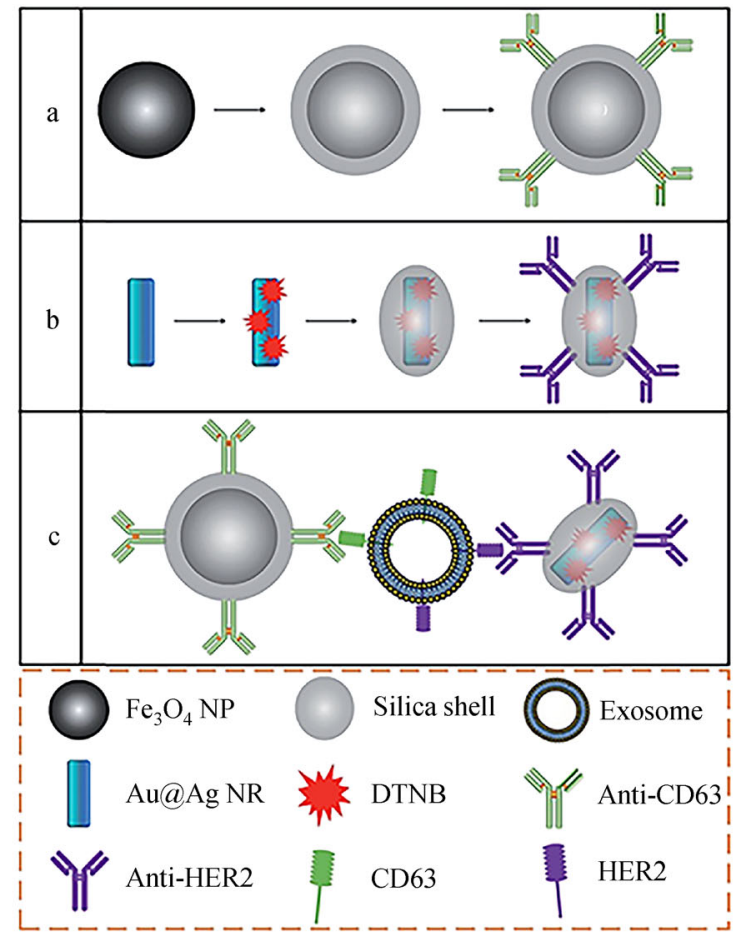

$\mathrm{C}$

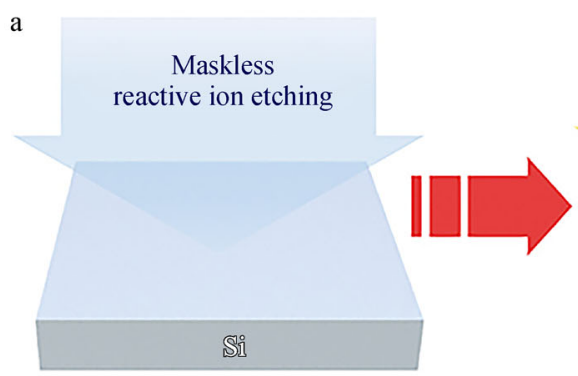

b

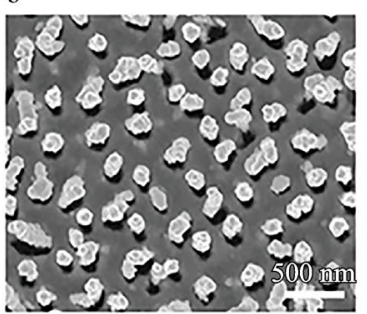

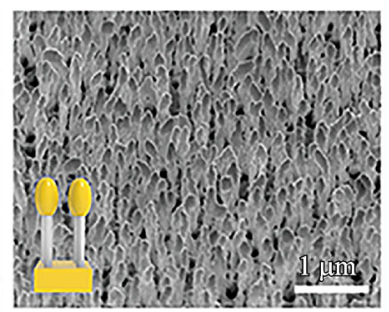

$\mathrm{c}$

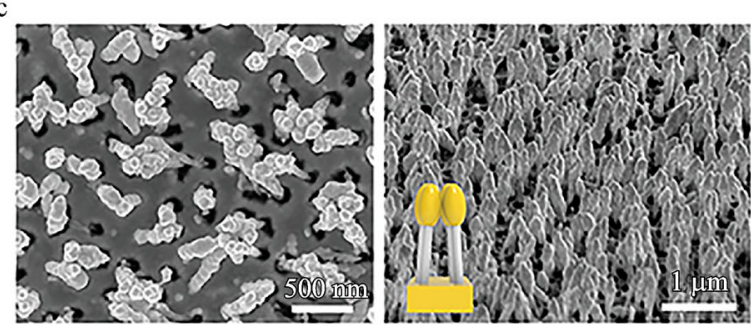

Fig. 5 Schematic of representative SERS-based biosensors. (A) Detection of cancer cells secreted exosomes based on Au nanoparticles decorated with a Raman reporter and magnetic beads with Au shell. (Reproduced with permission from Ref. [135]. Copyright 2018 the Royal Society of Chemistry.) (B) Detection of tumor-derived exosomes by using SERS nanoprobes with a core-shell structure and magnetic nanobeads. Diagram of the fabrication of (a) magnetic nanobead and (b) SERS nanoprobe. (c) Sandwich-type immunocomplex structure composed of exosome, magnetic nanobead, and SERS nanoprobe. Images are not to scale. (Reproduced with permission from Ref. [136]. Copyright 2016 the Royal Society of Chemistry.) (C) Detection of exosomal miRNAs based on plasmonic head-flocked gold nanopillars. (a) Fabrication process of plasmonic gold nanopillar SERS substrate. SEM images of (b) prepared plasmonic gold nanopillar SERS substrates and (c) plasmonic head-flocked gold nanopillar SERS substrates after solvent evaporation. (Reproduced with permission from Ref. [139]. Copyright 2019 Wiley.) 
integrating with the optimal exosome isolation method.

Exosomal nucleic acids are also important for the diagnosis of tumor, and they have been studied by many researchers by using SERS-based assays. For example, Ma et al. reported a new SERS analysis method using stable SERS reporter element and duplex-specific nucleasemediated signal amplification for the detection of exosomal miRNA extracted from human blood [138]. The stable SERS probes of $\mathrm{Au} @ \mathrm{R} 6 \mathrm{G} @ \mathrm{AgAu}$ nanoparticles were prepared by attaching R6G on GNPs and then encapsulated in AgAu alloy shell nanoparticles. The sensitivity of this sensing system was notably improved by the combination of stable SERS intensity and signal amplification. Similarly, Kwizera et al. fabricated a SERS-based sensing platform for quantitative determination of exosomal miRNAs on the basis of a uniform plasmonic headflocked gold nanopillar substrate, which could generate multiple hotspots after hybridization between short oligonucleotides (Fig. 5C) [139]. SERS tags are essential and indispensable to SERS biosensors. Thus, they have to be elaborately designed to improve sensitivity. In addition, portable Raman spectrometer is highly needed to make biosensors become commercialized for exosome detection in point-of-care diagnosis.

\section{Microfluidic-based biosensors}

Serving as novel manipulation techniques, microfluidicbased technologies have exhibited great promise in biological applications over the last several decades by manipulating fluids at submillimeter scale [140]. Microfluidic devices have the advantage of high-throughput analysis of biomolecules with high sensitivity, low reagent consumption, and short analysis time. With the rapid development of microfluidic techniques, excellent microfluidic-based biosensors integrated with various signal readout techniques have been developed [141]. For example, Kanwar et al. proposed an integrated microfluidic platform fabricated in PDMS. The platform was named ExoChip, which was modified with a specific antiCD63 antibody to capture exosomes, followed by staining the captured exosomes with a fluorescent carbocyanine dye (DiO) and quantitation of the concentrations by using a standard plate-reader [142]. This ExoChip allowed simultaneous capturing and quantification of circulating exosomes directly from blood serum. A microfluidic exosome analysis platform based on a new GO/PDA nano-interface was designed and fabricated by Zhang et al. to achieve ultrasensitive analysis of cancer cell-derived exosomes (Fig. 6A) [143]. In this microfluidic chip, the GO-induced formation of a 3D nanoporous PDA surface was prepared by the microfluidic layer-by-layer deposition of GO and PDA, which greatly improved the efficiency of exosome immuno-capture and effectively suppressed non-specific adsorption. On the basis of this nano-interface, an ultrasensitive assay was achieved for exosome detection, with a very low detection limit of 50 particles $/ \mu \mathrm{L}$.

The combination of colorimetric signal output and microfluidic technology may allow the visualization of exosomes with excellent performance. Vaidyanathan et al. proposed multiplexed microfluidic device by using a tunable alternating current electrohydrodynamic methodology for highly specific capture and detection of multiple exosomes (Fig. 6B) [144]. In this method, exosomes were captured on the surface of functionalized electrodes, and absorbance measurement of the colorimetric solution was performed for quantification. Woo et al. presented a rapid, label-free, and highly sensitive Exodisc platform that could be used to detect bladder cancer-related exosomes in a microfluidic chip with two-stage filtration process [145]. The signal of the microfluidic device could be recorded using a smart phone camera for colorimetric detection of the exosomes captured by the filter membrane to make the detection system convenient (Fig. 6C) [146]. One advantage of such a "lab-on-a-chip" standardization sequence is that the automation of separation, labeling, and detection operations could be performed on an effective platform.

SPR-based microfluidic techniques combine microfluidics and SPR, with advantages of rapid detection, portability, and label-free detection. Zhu et al. designed a SPR-based microfluidic chip for real-time and label-free quantification of multiple exosomal proteins without enrichment or purification process [147]. With the capture of exosomes by antibody microarrays modified on the gold surface, the refractive index of this biosensor could generate a huge change, which could be detected via SPR imaging. Meanwhile, nuclear magnetic resonance (NMR) is an important technique used in chemical and biomedicine analysis. The combination of NMR and microfluidics for exosome detection has also been developed with high reproducibility and sensitivity [148]. Besides, some electrochemical microfluidic-based biosensors that integrated electrochemical techniques with microfluidic platforms have shown remarkable performances in the detection of exosomes, with high sensitivity [149]. Microfluidic-implemented biosensors have shown better performances in terms of shorter operating time, smaller sample consumptions, and higher automation than bulk systems.

\section{Conclusion and perspectives}

Early diagnosis of cancer is important and indispensable in the improvement of therapeutic efficacy and patient survival. Selecting appropriate and specific biomarkers with sensitive and selective assay methods is essential. Exosomes containing various contents play important roles 
A

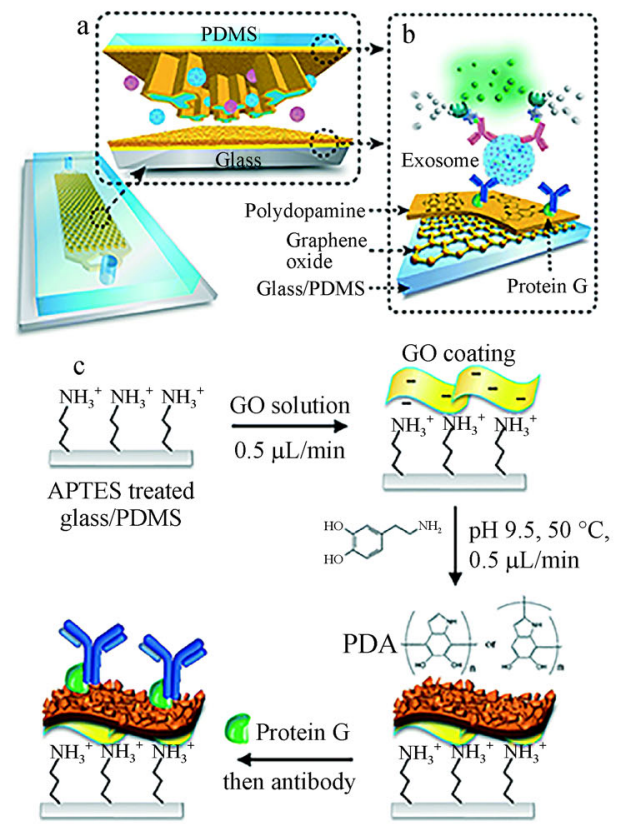

B
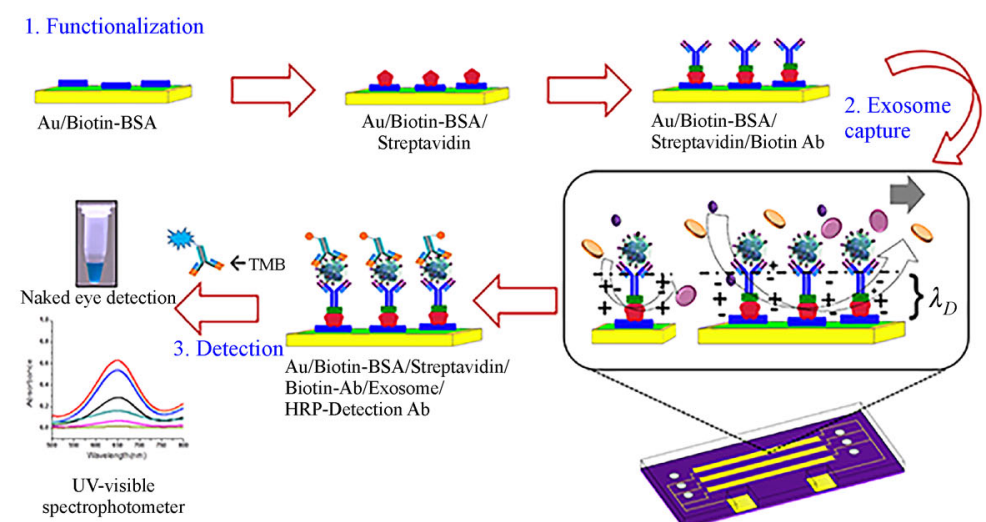

C
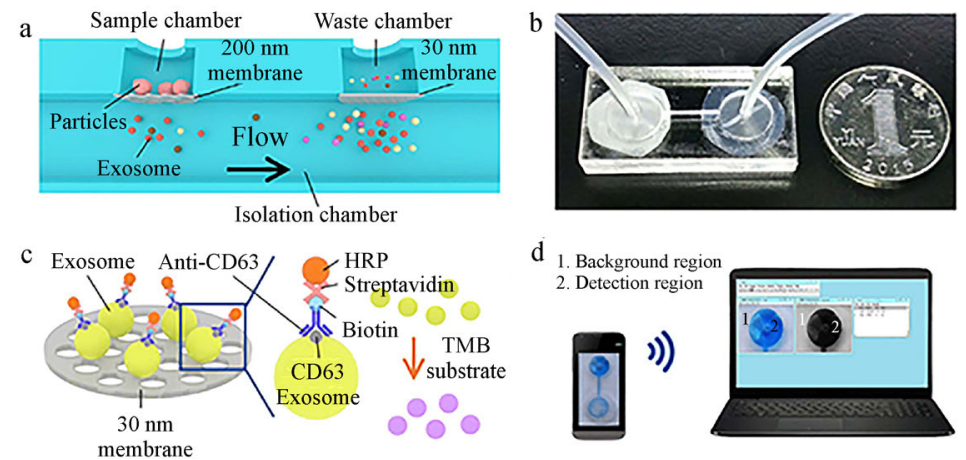

Fig. 6 Schematic of representative microfluidic-based biosensors. (A) Detection of circulating exosomes by using a nanostructured GO/ polydopamine functionalized microfluidic platform. Description of (a) a single-channel PDMS/glass chip containing an array of Y-shaped microposts and (b) channel and microposts coated with GO and polydopamine (PDA) as a nanostructured interface. (c) Procedure for surface functionalization of microfluidic chips. (Reproduced with permission from Ref. [143]. Copyright 2016 the Royal Society of Chemistry.) (B) Colorimetric detection of exosomes by using a tunable alternating current electrohydrodynamic methodology. (Reproduced with permission from Ref. [144]. Copyright 2014 American Chemical Society.) (C) Detection of exosomes from urine by using an integrated double-filtration microfluidic device. (a) Diagram of a double-filtration microfluidic device for isolation and detection of exosomes. (b) Size description of an assembled double-filtration device. (c) Diagram of direct ELISA for on-chip exosome detection. (d) The ELISA result is imaged via a smart phone, and then data analysis is conducted on a laptop. (Reproduced with permission from Ref.

[146]. Copyright 2017 Nature Publishing Group.)

in the development of cancer, hence considered as promising biomarkers. Significant progress has been made in the design and fabrication of various types of biosensors for the detection of exosomes, providing the basis for early and widespread screening of cancer. Herein, different types of biosensors for detecting cancer-derived exosomes in recent years were reviewed, with an emphasis on the sensitivity and selectivity of biosensors and their clinical application. Biosensor-based methods for exosome assays are notably becoming a promising alternative in the early diagnosis because of advantages, such as condensed detection time, simple operation, and low cost. However, some challenges are still needed to be addressed to convert laboratory methods to clinical applications.

For the future development of biosensors in detecting exosomes, researchers need to focus on the sensitivity, selectivity, biocompatibility, and anti-interference in clinical testing, because samples always contain a large number of cells, nucleic acids, proteins, and other components. Thus far, some multi-signal amplification methods have been proposed to improve sensitivity. Besides, the physiology and pathology are complex in cancer cells. Thus, the selectivity of diverse exosome markers for targeting different cancer types should be given attention. Combination of molecular pathological epidemiology, genomics, proteomics, and big data science could help acquire an enhanced understanding of the etiologies and pathogenesis of cancer and then select appropriate exosome markers [37,150]. Moreover, the biocompatibility of the sensing layer is critical to avoid immune response, especially in long-term detection in vivo. The future of biosensors for disease detection is directly oriented to a larger patient population. Therefore, devices need to be portable, user friendly, and inexpensive. Early screening of cancer could be in a new era with the rapid progress of biosensor-based assay technology, which 
could considerably improve the therapeutic effects and patient survival.

\section{Acknowledgements}

This work was supported by the National Natural Science Foundation of China (No. 81772593).

\section{Compliance with ethics guidelines}

Ying Deng, Zhaowei Sun, Lei Wang, Minghui Wang, Jie Yang, and Genxi Li declare that they have no conflict of interest. This manuscript is a review article and does not involve a research protocol requiring approval by the relevant institutional review board or ethics committee.

Open Access This article is licensed under a Creative Commons Attribution 4.0 International License, which permits use, sharing, adaptation, distribution and reproduction in any medium or format, as long as you give appropriate credit to the original author(s) and the source, provide a link to the Creative Commons license, and indicate if changes were made.

The images or other third party material in this article are included in the article's Creative Commons license, unless indicated otherwise in a credit line to the material. If material is not included in the article's Creative Commons license and your intended use is not permitted by statutory regulation or exceeds the permitted use, you will need to obtain permission directly from the copyright holder.

To view a copy of this license, visit https://creativecommons.org/ licenses/by/4.0/.

\section{References}

1. Miller KD, Siegel RL, Lin CC, Mariotto AB, Kramer JL, Rowland $\mathrm{JH}$, Stein KD, Alteri R, Jemal A. Cancer treatment and survivorship statistics, 2016. CA Cancer J Clin 2016; 66(4): 271-289

2. Hou J, Li X, Xie KP. Coupled liquid biopsy and bioinformatics for pancreatic cancer early detection and precision prognostication. Mol Cancer 2021; 20(1): 34

3. Liu C, Yang Y, Wu Y. Recent advances in exosomal protein detection via liquid biopsy biosensors for cancer screening, diagnosis, and prognosis. AAPS J 2018; 20(2): 41

4. Siravegna G, Marsoni S, Siena S, Bardelli A. Integrating liquid biopsies into the management of cancer. Nat Rev Clin Oncol 2017; 14(9): 531-548

5. Soda N, Rehm BHA, Sonar P, Nguyen NT, Shiddiky MJA. Advanced liquid biopsy technologies for circulating biomarker detection. J Mater Chem B Mater Biol Med 2019; 7(43): 66706704

6. Zhang L, Gu C, Wen J, Liu G, Liu H, Li L. Recent advances in nanomaterial-based biosensors for the detection of exosomes. Anal Bioanal Chem 2021; 413(1): 83-102

7. LeBleu VS, Kalluri R. Exosomes as a multicomponent biomarker platform in cancer. Trends Cancer 2020; 6(9): 767-774

8. Sharma A, Johnson A. Exosome DNA: critical regulator of tumor immunity and a diagnostic biomarker. J Cell Physiol 2020; 235(3): 1921-1932

9. Skotland T, Sagini K, Sandvig K, Llorente A. An emerging focus on lipids in extracellular vesicles. Adv Drug Deliv Rev 2020; 159: 308-321

10. Sandfeld-Paulsen B, Aggerholm-Pedersen N, Bæk R, Jakobsen KR, Meldgaard P, Folkersen BH, Rasmussen TR, Varming K, Jørgensen MM, Sorensen BS. Exosomal proteins as prognostic biomarkers in non-small cell lung cancer. Mol Oncol 2016; 10(10): 1595-1602

11. Colombo M, Raposo G, Théry C. Biogenesis, secretion, and intercellular interactions of exosomes and other extracellular vesicles. Annu Rev Cell Dev Biol 2014; 30(1): 255-289

12. Kalluri R, LeBleu VS. The biology, function, and biomedical applications of exosomes. Science 2020; 367(6478): eaau6977

13. Maacha S, Bhat AA, Jimenez L, Raza A, Haris M, Uddin S, Grivel JC. Extracellular vesicles-mediated intercellular communication: roles in the tumor microenvironment and anti-cancer drug resistance. Mol Cancer 2019; 18(1): 55

14. Meldolesi J. Exosomes and ectosomes in intercellular communication. Curr Biol 2018; 28(8): R435-R444

15. Quek C, Hill AF. The role of extracellular vesicles in neurodegenerative diseases. Biochem Biophys Res Commun 2017; 483(4): 1178-1186

16. Silva J, Garcia V, Rodriguez M, Compte M, Cisneros E, Veguillas P, Garcia JM, Dominguez G, Campos-Martin Y, Cuevas J, Peña C, Herrera M, Diaz R, Mohammed N, Bonilla F. Analysis of exosome release and its prognostic value in human colorectal cancer. Genes Chromosomes Cancer 2012; 51(4): 409-418

17. Yu W, Hurley J, Roberts D, Chakrabortty SK, Enderle D, Noerholm M, Breakefield XO, Skog JK. Exosome-based liquid biopsies in cancer: opportunities and challenges. Ann Oncol 2021; 32(4): 466-477

18. Khodashenas S, Khalili S, Forouzandeh Moghadam M. A cell ELISA based method for exosome detection in diagnostic and therapeutic applications. Biotechnol Lett 2019; 41(4-5): 523-531

19. Dragovic RA, Collett GP, Hole P, Ferguson DJ, Redman CW, Sargent IL, Tannetta DS. Isolation of syncytiotrophoblast microvesicles and exosomes and their characterisation by multicolour flow cytometry and fluorescence nanoparticle tracking analysis. Methods 2015; 87: 64-74

20. Chia BS, Low YP, Wang Q, Li P, Gao Z. Advances in exosome quantification techniques. Trends Analyt Chem 2017; 86: 93-106

21. Mastoridis S, Bertolino GM, Whitehouse G, Dazzi F, SanchezFueyo A, Martinez-Llordella M. Multiparametric analysis of circulating exosomes and other small extracellular vesicles by advanced imaging flow cytometry. Front Immunol 2018; 9: 1583

22. Luo X, An M, Cuneo KC, Lubman DM, Li L. High-performance chemical isotope labeling liquid chromatography mass spectrometry for exosome metabolomics. Anal Chem 2018; 90(14): 8314-8319

23. Ko J, Carpenter E, Issadore D. Detection and isolation of circulating exosomes and microvesicles for cancer monitoring and diagnostics using micro-/nano-based devices. Analyst (Lond) 2016; 141(2): 450-460 
24. Witwer KW, Buzás EI, Bemis LT, Bora A, Lässer C, Lötvall J, Nolte-'t Hoen EN, Piper MG, Sivaraman S, Skog J, Théry C, Wauben $\mathrm{MH}$, Hochberg F. Standardization of sample collection, isolation and analysis methods in extracellular vesicle research. J Extracell Vesicles 2013; 2: 20360

25. Sun Z, Wang L, Wu S, Pan Y, Dong Y, Zhu S, Yang J, Yin Y, Li G. An electrochemical biosensor designed by using Zr-based metalorganic frameworks for the detection of glioblastoma-derived exosomes with practical application. Anal Chem 2020; 92(5): 3819-3826

26. Wang L, Pan Y, Liu Y, Sun Z, Huang Y, Li J, Yang J, Xiang Y, Li G. Fabrication of an aptamer-coated liposome complex for the detection and profiling of exosomes based on terminal deoxynucleotidyl transferase-mediated signal amplification. ACS Appl Mater Interfaces 2020; 12(1): 322-329

27. van der Pol E, Coumans F A W, Grootemaat AE, Gardiner C, Sargent IL, Harrison P, Sturk A, van Leeuwen TG, Nieuwland R. Particle size distribution of exosomes and microvesicles determined by transmission electron microscopy, flow cytometry, nanoparticle tracking analysis, and resistive pulse sensing. J Thromb Haemost 2014; 12(7): 1182-1192

28. Lin S, Yu Z, Chen D, Wang Z, Miao J, Li Q, Zhang D, Song J, Cui D. Progress in microfluidics-based exosome separation and detection technologies for diagnostic applications. Small 2020; 16(9): e1903916

29. Yoo SM, Lee SY. Optical biosensors for the detection of pathogenic microorganisms. Trends Biotechnol 2016; 34(1): 7-25

30. Masud MK, Na J, Younus M, Hossain MSA, Bando Y, Shiddiky MJA, Yamauchi Y. Superparamagnetic nanoarchitectures for disease-specific biomarker detection. Chem Soc Rev 2019; 48 (24): 5717-5751

31. Huang Y, Wang L, Sha L, Wang Y, Duan X, Li G. Highly sensitive detection of lipopolysaccharide based on collaborative amplification of dual enzymes. Anal Chim Acta 2020; 1126: 31-37

32. Geng Y, Peveler WJ, Rotello VM. Array-based "chemical nose" sensing in diagnostics and drug discovery. Angew Chem Int Ed Engl 2019; 58(16): 5190-5200

33. Wu J, Hu S, Zhang L, Xin J, Sun C, Wang L, Ding K, Wang B. Tumor circulome in the liquid biopsies for cancer diagnosis and prognosis. Theranostics 2020; 10(10): 4544-4556

34. Guo SC, Tao SC, Dawn H. Microfluidics-based on-a-chip systems for isolating and analysing extracellular vesicles. J Extracell Vesicles 2018; 7(1): 1508271

35. Cheng N, Du D, Wang X, Liu D, Xu W, Luo Y, Lin Y. Recent advances in biosensors for detecting cancer-derived exosomes. Trends Biotechnol 2019; 37(11): 1236-1254

36. Wen W, Yan X, Zhu C, Du D, Lin Y. Recent advances in electrochemical immunosensors. Anal Chem 2017; 89(1): 138156

37. Ogino S, Nowak JA, Hamada T Jr, Milner DA Jr, Nishihara R. Insights into pathogenic interactions among environment, host, and tumor at the crossroads of molecular pathology and epidemiology. Annu Rev Pathol 2019; 14(1): 83-103

38. Zhang L, Gu C, Wen J, Liu G, Liu H, Li L. Recent advances in nanomaterial-based biosensors for the detection of exosomes. Anal Bioanal Chem 2021; 413(1): 83-102

39. Balaj L, Lessard R, Dai L, Cho YJ, Pomeroy SL, Breakefield XO,
Skog J. Tumour microvesicles contain retrotransposon elements and amplified oncogene sequences. Nat Commun 2011; 2(1): 180

40. Mathieu M, Martin-Jaular L, Lavieu G, Théry C. Specificities of secretion and uptake of exosomes and other extracellular vesicles for cell-to-cell communication. Nat Cell Biol 2019; 21(1): 9-17

41. Wolf $\mathrm{P}$. The nature and significance of platelet products in human plasma. Br J Haematol 1967; 13(3): 269-288

42. Johnstone RM, Adam M, Hammond JR, Orr L, Turbide C. Vesicle formation during reticulocyte maturation. Association of plasma membrane activities with released vesicles (exosomes). J Biol Chem 1987; 262(19): 9412-9420

43. Kowal J, Tkach M, Théry C. Biogenesis and secretion of exosomes. Curr Opin Cell Biol 2014; 29: 116-125

44. Foster BP, Balassa T, Benen TD, Dominovic M, Elmadjian GK, Florova V, Fransolet MD, Kestlerova A, Kmiecik G, Kostadinova IA, Kyvelidou C, Meggyes M, Mincheva MN, Moro L, Pastuschek J, Spoldi V, Wandernoth P, Weber M, Toth B, Markert UR. Extracellular vesicles in blood, milk and body fluids of the female and male urogenital tract and with special regard to reproduction. Crit Rev Clin Lab Sci 2016; 53(6): 379-395

45. Delorme-Axford E, Donker RB, Mouillet JF, Chu T, Bayer A, Ouyang Y, Wang T, Stolz DB, Sarkar SN, Morelli AE, Sadovsky Y, Coyne CB. Human placental trophoblasts confer viral resistance to recipient cells. Proc Natl Acad Sci USA 2013; 110(29): 1204812053

46. Gehrmann U, Näslund TI, Hiltbrunner S, Larssen P, Gabrielsson S. Harnessing the exosome-induced immune response for cancer immunotherapy. Semin Cancer Biol 2014; 28: 58-67

47. Cheng Y, Schorey JS. Extracellular vesicles deliver Mycobacterium RNA to promote host immunity and bacterial killing. EMBO Rep 2019; 20(3): e46613

48. de Carvalho JV, de Castro RO, da Silva EZ, Silveira PP, da SilvaJanuário ME, Arruda E, Jamur MC, Oliver C, Aguiar RS, daSilva LL. Nef neutralizes the ability of exosomes from $\mathrm{CD} 4^{+} \mathrm{T}$ cells to act as decoys during HIV-1 infection. PLoS One 2014; 9(11): e113691

49. Guay C, Regazzi R. Exosomes as new players in metabolic organ cross-talk. Diabetes Obes Metab 2017; 19(Suppl 1): 137-146

50. Zhang Y, Hu YW, Zheng L, Wang Q. Characteristics and roles of exosomes in cardiovascular disease. DNA Cell Biol 2017; 36(3): 202-211

51. Budnik V, Ruiz-Cañada C, Wendler F. Extracellular vesicles round off communication in the nervous system. Nat Rev Neurosci 2016; 17(3): 160-172

52. Sundararajan V, Sarkar FH, Ramasamy TS. The multifaceted role of exosomes in cancer progression: diagnostic and therapeutic implications [corrected]. Cell Oncol (Dordr) 2018; 41(3): 223-252

53. Yang Y, Li CW, Chan LC, Wei Y, Hsu JM, Xia W, Cha JH, Hou J, Hsu JL, Sun L, Hung MC. Exosomal PD-L1 harbors active defense function to suppress $\mathrm{T}$ cell killing of breast cancer cells and promote tumor growth. Cell Res 2018; 28(8): 862-864

54. Fang T, Lv H, Lv G, Li T, Wang C, Han Q, Yu L, Su B, Guo L, Huang S, Cao D, Tang L, Tang S, Wu M, Yang W, Wang H. Tumor-derived exosomal miR-1247-3p induces cancer-associated fibroblast activation to foster lung metastasis of liver cancer. Nat Commun 2018; 9(1): 191

55. Liu X, Lu Y, Xu Y, Hou S, Huang J, Wang B, Zhao J, Xia S, Fan S, 
Yu X, Du Y, Hou L, Li Z, Ding Z, An S, Huang B, Li L, Tang J, Ju J, Guan H, Song B. Exosomal transfer of miR-501 confers doxorubicin resistance and tumorigenesis via targeting of BLID in gastric cancer. Cancer Lett 2019; 459: 122-134

56. Al-Nedawi K, Meehan B, Micallef J, Lhotak V, May L, Guha A, Rak J. Intercellular transfer of the oncogenic receptor EGFRvIII by microvesicles derived from tumour cells. Nat Cell Biol 2008; 10 (5): 619-624

57. Jakobsen KR, Paulsen BS, Bæk R, Varming K, Sorensen BS, Jørgensen MM. Exosomal proteins as potential diagnostic markers in advanced non-small cell lung carcinoma. J Extracell Vesicles 2015; 4(1): 26659

58. Melo SA, Luecke LB, Kahlert C, Fernandez AF, Gammon ST, Kaye J, LeBleu VS, Mittendorf EA, Weitz J, Rahbari N, Reissfelder C, Pilarsky C, Fraga MF, Piwnica-Worms D, Kalluri R. Glypican-1 identifies cancer exosomes and detects early pancreatic cancer. Nature 2015; 523(7559): 177-182

59. Yoon JH, Ham IH, Kim O, Ashktorab H, Smoot DT, Nam SW, Lee JY, Hur H, Park WS. Gastrokine 1 protein is a potential theragnostic target for gastric cancer. Gastric Cancer 2018; 21(6): 956-967

60. Khan S, Bennit HF, Turay D, Perez M, Mirshahidi S, Yuan Y, Wall NR. Early diagnostic value of survivin and its alternative splice variants in breast cancer. BMC Cancer 2014; 14(1): 176

61. Zhang P, Zhou X, He M, Shang Y, Tetlow AL, Godwin AK, Zeng Y. Ultrasensitive detection of circulating exosomes with a 3Dnanopatterned microfluidic chip. Nat Biomed Eng 2019; 3(6): 438-451

62. Mitchell PS, Parkin RK, Kroh EM, Fritz BR, Wyman SK, Pogosova-Agadjanyan EL, Peterson A, Noteboom J, O'Briant KC, Allen A, Lin DW, Urban N, Drescher CW, Knudsen BS, Stirewalt DL, Gentleman R, Vessella RL, Nelson PS, Martin DB, Tewari M. Circulating microRNAs as stable blood-based markers for cancer detection. Proc Natl Acad Sci USA 2008; 105(30): 10513-10518

63. Sun Z, Shi K, Yang S, Liu J, Zhou Q, Wang G, Song J, Li Z, Zhang Z, Yuan W. Effect of exosomal miRNA on cancer biology and clinical applications. Mol Cancer 2018; 17(1): 147

64. Li Z, Ma YY, Wang J, Zeng XF, Li R, Kang W, Hao XK. Exosomal microRNA-141 is upregulated in the serum of prostate cancer patients. Onco Targets Ther 2015; 9: 139-148

65. Zhou CF, Ma J, Huang L, Yi HY, Zhang YM, Wu XG, Yan RM, Liang L, Zhong M, Yu YH, Wu S, Wang W. Cervical squamous cell carcinoma-secreted exosomal miR-221-3p promotes lymphangiogenesis and lymphatic metastasis by targeting VASH1. Oncogene 2019; 38(8): 1256-1268

66. Wang X, Luo G, Zhang K, Cao J, Huang C, Jiang T, Liu B, Su L, Qiu Z. Hypoxic tumor-derived exosomal miR-301a mediates M2 macrophage polarization via PTEN/PI3K $\gamma$ to promote pancreatic cancer metastasis. Cancer Res 2018; 78(16): 4586-4598

67. Hanahan D, Weinberg RA. Hallmarks of cancer: the next generation. Cell 2011; 144(5): 646-674

68. Boriachek K, Umer M, Islam MN, Gopalan V, Lam AK, Nguyen NT, Shiddiky MJA. An amplification-free electrochemical detection of exosomal miRNA-21 in serum samples. Analyst (Lond) 2018; 143(7): 1662-1669

69. Li Y, Zhang Y, Qiu F, Qiu Z. Proteomic identification of exosomal LRG1: a potential urinary biomarker for detecting NSCLC.
Electrophoresis 2011; 32(15): 1976-1983

70. Kim HK, Jeong H, Choi BH, Quan YH, Rho J, Park JH, Park Y, Choi Y, Han KN, Choi YH, Hong S. Lung cancer exosome specific protein 1 (LESP-1) as a potential factor for diagnosis and treatment of non-small cell lung cancer. J Clin Oncol 2020; 38(15_suppl): e15550

71. Tian Y, Ma L, Gong M, Su G, Zhu S, Zhang W, Wang S, Li Z, Chen $\mathrm{C}, \mathrm{Li} \mathrm{L}, \mathrm{Wu} \mathrm{L}$, Yan X. Protein profiling and sizing of extracellular vesicles from colorectal cancer patients via flow cytometry. ACS Nano 2018; 12(1): 671-680

72. Khan S, Bennit HF, Turay D, Perez M, Mirshahidi S, Yuan Y, Wall NR. Early diagnostic value of survivin and its alternative splice variants in breast cancer. BMC Cancer 2014; 14(1): 176

73. Taylor DD, Gercel-Taylor C. MicroRNA signatures of tumorderived exosomes as diagnostic biomarkers of ovarian cancer. Gynecol Oncol 2008; 110(1): 13-21

74. Zhou X, Wen W, Shan X, Zhu W, Xu J, Guo R, Cheng W, Wang F, Qi LW, Chen Y, Huang Z, Wang T, Zhu D, Liu P, Shu Y. A sixmicroRNA panel in plasma was identified as a potential biomarker for lung adenocarcinoma diagnosis. Oncotarget 2017; 8(4): 65136525

75. Miranda-Castro R, Palchetti I, de-Los-Santos-Álvarez N. The translational potential of electrochemical DNA-based liquid biopsy. Front Chem 2020; 8: 143

76. Díaz-Fernández A, Lorenzo-Gómez R, Miranda-Castro R, de-LosSantos-Álvarez N, Lobo-Castañón MJ. Electrochemical aptasensors for cancer diagnosis in biological fluids - a review. Anal Chim Acta 2020; 1124: 1-19

77. Abi A, Mohammadpour Z, Zuo X, Safavi A. Nucleic acid-based electrochemical nanobiosensors. Biosens Bioelectron 2018; 102: 479-489

78. Yin X, Hou T, Huang B, Yang L, Li F. Aptamer recognitiontrigged label-free homogeneous electrochemical strategy for an ultrasensitive cancer-derived exosome assay. Chem Commun (Camb) 2019; 55(91): 13705-13708

79. Dong H, Chen H, Jiang J, Zhang H, Cai C, Shen Q. Highly sensitive electrochemical detection of tumor exosomes based on aptamer recognition-induced multi-DNA release and cyclic enzymatic amplification. Anal Chem 2018; 90(7): 4507-4513

80. Zhao L, Sun R, He P, Zhang X. Ultrasensitive detection of exosomes by target-triggered three-dimensional DNA walking machine and exonuclease III-assisted electrochemical ratiometric biosensing. Anal Chem 2019; 91(22): 14773-14779

81. Wang L, Zeng L, Wang Y, Chen T, Chen W, Chen G, Li C, Chen J. Electrochemical aptasensor based on multidirectional hybridization chain reaction for detection of tumorous exosomes. Sens Actuators B Chem 2021; 332: 129471

82. An Y, Jin T, Zhu Y, Zhang F, He P. An ultrasensitive electrochemical aptasensor for the determination of tumor exosomes based on click chemistry. Biosens Bioelectron 2019; 142: 111503

83. Cao Y, Li L, Han B, Wang Y, Dai Y, Zhao J. A catalytic molecule machine-driven biosensing method for amplified electrochemical detection of exosomes. Biosens Bioelectron 2019; 141: 111397

84. McLean MH, El-Omar EM. Genetics of gastric cancer. Nat Rev Gastroenterol Hepatol 2014; 11(11): 664-674

85. Huang R, He L, Xia Y, Xu H, Liu C, Xie H, Wang S, Peng L, Liu 
Y, Liu Y, He N, Li Z. A sensitive aptasensor based on a hemin/Gquadruplex-assisted signal amplification strategy for electrochemical detection of gastric cancer exosomes. Small 2019; 15(19): e1900735

86. Wang L, Deng Y, Wei J, Huang Y, Wang Z, Li G. Spherical nucleic acids-based cascade signal amplification for highly sensitive detection of exosomes. Biosens Bioelectron 2021; 191: 113465

87. Maduraiveeran G, Sasidharan M, Ganesan V. Electrochemical sensor and biosensor platforms based on advanced nanomaterials for biological and biomedical applications. Biosens Bioelectron 2018; 103: 113-129

88. Kreno LE, Leong K, Farha OK, Allendorf M, Van Duyne RP, Hupp JT. Metal-organic framework materials as chemical sensors. Chem Rev 2012; 112(2): 1105-1125

89. Heck JG, Napp J, Simonato S, Möllmer J, Lange M, Reichardt HM, Staudt R, Alves F, Feldmann C. Multifunctional phosphatebased inorganic-organic hybrid nanoparticles. J Am Chem Soc 2015; 137(23): 7329-7336

90. Mao J, Ran D, Xie C, Shen Q, Wang S, Lu W. EGFR/EGFRvIII dual-targeting peptide-mediated drug delivery for enhanced glioma therapy. ACS Appl Mater Interfaces 2017; 9(29): 24462-24475

91. Cheng G, Li W, Ha L, Han X, Hao S, Wan Y, Wang Z, Dong F, Zou X, Mao Y, Zheng SY. Self-assembly of extracellular vesiclelike metal-organic framework nanoparticles for protection and intracellular delivery of biofunctional proteins. J Am Chem Soc 2018; 140(23): 7282-7291

92. Cao Y, Wang Y, Yu X, Jiang X, Li G, Zhao J. Identification of programmed death ligand-1 positive exosomes in breast cancer based on DNA amplification-responsive metal-organic frameworks. Biosens Bioelectron 2020; 166: 112452

93. Kandambeth S, Dey K, Banerjee R. Covalent organic frameworks: chemistry beyond the structure. J Am Chem Soc 2019; 141(5): $1807-1822$

94. Wang M, Pan Y, Wu S, Sun Z, Wang L, Yang J, Yin Y, Li G. Detection of colorectal cancer-derived exosomes based on covalent organic frameworks. Biosens Bioelectron 2020; 169: 112638

95. Farhana FZ, Umer M, Saeed A, Pannu AS, Shahbazi M, Jabur A, Nam HJ, Ostrikov K, Sonar P, Firoz SH, Shiddiky MJA. Isolation and detection of exosomes using $\mathrm{Fe}_{2} \mathrm{O}_{3}$ nanoparticles. ACS Appl Nano Mater 2021; 4(2): 1175-1186

96. Xu L, Shoaie N, Jahanpeyma F, Zhao J, Azimzadeh M, Al Jamal KT. Optical, electrochemical and electrical (nano)biosensors for detection of exosomes: a comprehensive overview. Biosens Bioelectron 2020; 161: 112222

97. Kholafazad Kordasht H, Hasanzadeh M. Biomedical analysis of exosomes using biosensing methods: recent progress. Anal Methods 2020; 12(22): 2795-2811

98. Panagopoulou MS, Wark AW, Birch DJS, Gregory CD. Phenotypic analysis of extracellular vesicles: a review on the applications of fluorescence. J Extracell Vesicles 2020; 9(1): 1710020

99. Wang L, Yang Y, Liu Y, Ning L, Xiang Y, Li G. Bridging exosome and liposome through zirconium-phosphate coordination chemistry: a new method for exosome detection. Chem Commun (Camb) 2019; 55(18): 2708-2711

100. Yu X, He L, Pentok M, Yang H, Yang Y, Li Z, He N, Deng Y, Li S, Liu T, Chen X, Luo H. An aptamer-based new method for competitive fluorescence detection of exosomes. Nanoscale 2019;
11(33): 15589-15595

101. Pan Y, Wang L, Deng Y, Wang M, Peng Y, Yang J, Li G. A simple and sensitive method for exosome detection based on steric hindrance-controlled signal amplification. Chem Commun (Camb) 2020; 56(89): 13768-13771

102. Tian W, Li P, He W, Liu C, Li Z. Rolling circle extension-actuated loop-mediated isothermal amplification (RCA-LAMP) for ultrasensitive detection of microRNAs. Biosens Bioelectron 2019; 128 : $17-22$

103. Huang L, Wang DB, Singh N, Yang F, Gu N, Zhang XE. A dualsignal amplification platform for sensitive fluorescence biosensing of leukemia-derived exosomes. Nanoscale 2018; 10(43): 2028920295

104. Huang R, He L, Li S, Liu H, Jin L, Chen Z, Zhao Y, Li Z, Deng Y, $\mathrm{HeN}$. A simple fluorescence aptasensor for gastric cancer exosome detection based on branched rolling circle amplification. Nanoscale 2020; 12(4): 2445-2451

105. Zhang J, Shi J, Liu W, Zhang K, Zhao H, Zhang H, Zhang Z. A simple, specific and "on-off" type MUC1 fluorescence aptasensor based on exosomes for detection of breast cancer. Sens Actuators B Chem 2018; 276: 552-559

106. Li P, Yu X, Han W, Kong Y, Bao W, Zhang J, Zhang W, Gu Y. Ultrasensitive and reversible nanoplatform of urinary exosomes for prostate cancer diagnosis. ACS Sens 2019; 4(5): 1433-1441

107. Yu Y, Zhang WS, Guo Y, Peng H, Zhu M, Miao D, Su G. Engineering of exosome-triggered enzyme-powered DNA motors for highly sensitive fluorescence detection of tumor-derived exosomes. Biosens Bioelectron 2020; 167: 112482

108. Li B, Liu C, Pan W, Shen J, Guo J, Luo T, Feng J, Situ B, An T, Zhang Y, Zheng L. Facile fluorescent aptasensor using aggregation-induced emission luminogens for exosomal proteins profiling towards liquid biopsy. Biosens Bioelectron 2020; 168: 112520

109. Zhang Z, Tang C, Zhao L, Xu L, Zhou W, Dong Z, Yang Y, Xie Q, Fang X. Aptamer-based fluorescence polarization assay for separation-free exosome quantification. Nanoscale 2019; 11(20): 10106-10113

110. Liang $X$, Han L. White peroxidase-mimicking nanozymes: colorimetric pesticide assay without interferences of $\mathrm{O}_{2}$ and color. Adv Funct Mater 2020; 30(28): 2001933

111. Xu L, Chopdat R, Li D, Al-Jamal KT. Development of a simple, sensitive and selective colorimetric aptasensor for the detection of cancer-derived exosomes. Biosens Bioelectron 2020; 169: 112576

112. Mokhtarzadeh A, Ezzati Nazhad Dolatabadi J, Abnous K, de la Guardia M, Ramezani M. Nanomaterial-based cocaine aptasensors. Biosens Bioelectron 2015; 68: 95-106

113. Liu W, Li J, Wu Y, Xing S, Lai Y, Zhang G. Target-induced proximity ligation triggers recombinase polymerase amplification and transcription-mediated amplification to detect tumor-derived exosomes in nasopharyngeal carcinoma with high sensitivity. Biosens Bioelectron 2018; 102: 204-210

114. Li J, Baird MA, Davis MA, Tai W, Zweifel LS, Adams Waldorf KM, Gale M Jr, Rajagopal L, Pierce RH, Gao X. Dramatic enhancement of the detection limits of bioassays via ultrafast deposition of polydopamine. Nat Biomed Eng 2017; 1: 0082

115. Lee H, Rho J, Messersmith PB. Facile conjugation of biomolecules onto surfaces via mussel adhesive protein inspired coatings. Adv Mater 2009; 21(4): 431-434 
116. Chen Z, Cheng SB, Cao P, Qiu QF, Chen Y, Xie M, Xu Y, Huang WH. Detection of exosomes by $\mathrm{ZnO}$ nanowires coated threedimensional scaffold chip device. Biosens Bioelectron 2018; 122: 211-216

117. He F, Liu H, Guo X, Yin BC, Ye BC. Direct exosome quantification via bivalent-cholesterol-labeled DNA anchor for signal amplification. Anal Chem 2017; 89(23): 12968-12975

118. Zhang Y, Wang D, Yue S, Lu Y, Yang C, Fang J, Xu Z. Sensitive multicolor visual detection of exosomes via dual signal amplification strategy of enzyme-catalyzed metallization of $\mathrm{Au}$ nanorods and hybridization chain reaction. ACS Sens 2019; 4(12): 32103218

119. Zhang Y, Jiao J, Wei Y, Wang D, Yang C, Xu Z. Plasmonic colorimetric biosensor for sensitive exosome detection via enzymeinduced etching of gold nanobipyramid@ $\mathrm{MnO}_{2}$ nanosheet nanostructures. Anal Chem 2020; 92(22): 15244-15252

120. Munir S, Shah AA, Rahman H, Bilal M, Rajoka MSR, Khan AA, Khurshid M. Nanozymes for medical biotechnology and its potential applications in biosensing and nanotherapeutics. Biotechnol Lett 2020; 42(3): 357-373

121. Chen $\mathrm{J}, \mathrm{Xu} \mathrm{Y}, \mathrm{Lu} \mathrm{Y}, \mathrm{Xing} \mathrm{W}$. Isolation and visible detection of tumor-derived exosomes from plasma. Anal Chem 2018; 90(24): 14207-14215

122. Boriachek K, Masud MK, Palma C, Phan HP, Yamauchi Y, Hossain MSA, Nguyen NT, Salomon C, Shiddiky MJA. Avoiding pre-isolation step in exosome analysis: direct isolation and sensitive detection of exosomes using gold-loaded nanoporous ferric oxide nanozymes. Anal Chem 2019; 91(6): 3827-3834

123. Wang YM, Liu JW, Adkins GB, Shen W, Trinh MP, Duan LY, Jiang JH, Zhong W. Enhancement of the intrinsic peroxidase-like activity of graphitic carbon nitride nanosheets by ssDNAs and its application for detection of exosomes. Anal Chem 2017; 89(22): 12327-12333

124. Xia Y, Liu M, Wang L, Yan A, He W, Chen M, Lan J, Xu J, Guan L, Chen J. A visible and colorimetric aptasensor based on DNAcapped single-walled carbon nanotubes for detection of exosomes. Biosens Bioelectron 2017; 92: 8-15

125. Zhou Y, Xu H, Wang H, Ye BC. Detection of breast cancer-derived exosomes using the horseradish peroxidase-mimicking DNAzyme as an aptasensor. Analyst (Lond) 2020; 145: 107-114

126. Masson JF. Surface plasmon resonance clinical biosensors for medical diagnostics. ACS Sens 2017; 2(1): 16-30

127. Singh P, Biosensors SPR. Historical perspectives and current challenges. Sens Actuators B Chem 2016; 229: 110-130

128. Kabashin AV, Evans P, Pastkovsky S, Hendren W, Wurtz GA, Atkinson R, Pollard R, Podolskiy VA, Zayats AV. Plasmonic nanorod metamaterials for biosensing. Nat Mater 2009; 8(11): $867-871$

129. Wang Q, Zou L, Yang X, Liu X, Nie W, Zheng Y, Cheng Q, Wang K. Direct quantification of cancerous exosomes via surface plasmon resonance with dual gold nanoparticle-assisted signal amplification. Biosens Bioelectron 2019; 135: 129-136

130. Thakur A, Qiu G, Ng SP, Guan J, Yue J, Lee Y, Wu CL. Direct detection of two different tumor-derived extracellular vesicles by SAM-AuNIs LSPR biosensor. Biosens Bioelectron 2017; 94: 400407

131. Qiu G, Thakur A, Xu C, Ng SP, Lee Y, Wu CML. Detection of glioma-derived exosomes with the biotinylated antibody-functionalized titanium nitride plasmonic biosensor. Adv Funct Mater 2019; 29(9): 1806761

132. Im H, Shao H, Park YI, Peterson VM, Castro CM, Weissleder R, Lee H. Label-free detection and molecular profiling of exosomes with a nano-plasmonic sensor. Nat Biotechnol 2014; 32(5): 490495

133. Zong S, Wang Z, Chen H, Cui Y. Ultrasensitive telomerase activity detection by telomeric elongation controlled surface enhanced Raman scattering. Small 2013; 9(24): 4215-4220

134. Cialla-May D, Zheng XS, Weber K, Popp J. Recent progress in surface-enhanced Raman spectroscopy for biological and biomedical applications: from cells to clinics. Chem Soc Rev 2017; 46 (13): 3945-3961

135. Wang Z, Zong S, Wang Y, Li N, Li L, Lu J, Wang Z, Chen B, Cui Y. Screening and multiple detection of cancer exosomes using an SERS-based method. Nanoscale 2018; 10(19): 9053-9062

136. Zong S, Wang L, Chen C, Lu J, Zhu D, Zhang Y, Wang Z, Cui Y. Facile detection of tumor-derived exosomes using magnetic nanobeads and SERS nanoprobes. Anal Methods 2016; 8(25): 5001-5008

137. Kwizera EA, O'Connor R, Vinduska V, Williams M, Butch ER, Snyder SE, Chen X, Huang X. Molecular detection and analysis of exosomes using surface-enhanced Raman scattering gold nanorods and a miniaturized device. Theranostics 2018; 8(10): 2722-2738

138. Ma D, Huang C, Zheng J, Tang J, Li J, Yang J, Yang R. Quantitative detection of exosomal microRNA extracted from human blood based on surface-enhanced Raman scattering. Biosens Bioelectron 2018; 101: 167-173

139. Lee JU, Kim WH, Lee HS, Park KH, Sim SJ. Quantitative and specific detection of exosomal miRNAs for accurate diagnosis of breast cancer using a surface-enhanced Raman scattering sensor based on plasmonic head-flocked gold nanopillars. Small 2019; 15 (17): e1804968

140. Sackmann EK, Fulton AL, Beebe DJ. The present and future role of microfluidics in biomedical research. Nature 2014; 507(7491): 181-189

141. Chen W, Shao F, Xianyu Y. Microfluidics-implemented biochemical assays: from the perspective of readout. Small 2020; 16(9): e1903388

142. Kanwar SS, Dunlay CJ, Simeone DM, Nagrath S. Microfluidic device (ExoChip) for on-chip isolation, quantification and characterization of circulating exosomes. Lab Chip 2014; 14(11): 1891-1900

143. Zhang P, He M, Zeng Y. Ultrasensitive microfluidic analysis of circulating exosomes using a nanostructured graphene oxide/ polydopamine coating. Lab Chip 2016; 16(16): 3033-3042

144. Vaidyanathan R, Naghibosadat M, Rauf S, Korbie D, Carrascosa LG, Shiddiky MJA, Trau M. Detecting exosomes specifically: a multiplexed device based on alternating current electrohydrodynamic induced nanoshearing. Anal Chem 2014; 86(22): 1112511132

145. Woo HK, Sunkara V, Park J, Kim TH, Han JR, Kim CJ, Choi HI, Kim YK, Cho YK. Exodisc for rapid, size-selective, and efficient isolation and analysis of nanoscale extracellular vesicles from biological samples. ACS Nano 2017; 11(2): 1360-1370

146. Liang LG, Kong MQ, Zhou S, Sheng YF, Wang P, Yu T, Inci F, 
Kuo WP, Li LJ, Demirci U, Wang S. An integrated doublefiltration microfluidic device for isolation, enrichment and quantification of urinary extracellular vesicles for detection of bladder cancer. Sci Rep 2017; 7(1): 46224

147. Zhu L, Wang K, Cui J, Liu H, Bu X, Ma H, Wang W, Gong H, Lausted C, Hood L, Yang G, Hu Z. Label-free quantitative detection of tumor-derived exosomes through surface plasmon resonance imaging. Anal Chem 2014; 86(17): 8857-8864

148. Shao H, Chung J, Balaj L, Charest A, Bigner DD, Carter BS, Hochberg FH, Breakefield XO, Weissleder R, Lee H. Protein typing of circulating microvesicles allows real-time monitoring of glioblastoma therapy. Nat Med 2012; 18(12): 1835-1840

149. Shin SR, Kilic T, Zhang YS, Avci H, Hu N, Kim D, Branco C, Aleman J, Massa S, Silvestri A, Kang J, Desalvo A, Hussaini MA, Chae SK, Polini A, Bhise N, Hussain MA, Lee H, Dokmeci MR, Khademhosseini A. Label-free and regenerative electrochemical microfluidic biosensors for continual monitoring of cell secretomes. Adv Sci (Weinh) 2017; 4(5): 1600522

150. Hamada T, Keum N, Nishihara R, Ogino S. Molecular pathological epidemiology: new developing frontiers of big data science to study etiologies and pathogenesis. J Gastroenterol 2017; 52(3): 265-275 